Universidade de São Paulo

Escola Superior de Agricultura "Luiz de Queiroz"

Redistribuição de nutrientes em razão da fenologia da frutificação do café arábica

\title{
Marina Rodrigues dos Reis
}

Dissertação apresentada para obtenção do título de Mestra em Ciências. Área de concentração: Fitotecnia

\section{Piracicaba}




\section{Marina Rodrigues dos Reis \\ Engenheira Agrônoma}

Redistribuição de nutrientes em razão da fenologia da frutificação do café arábica versão revisada de acordo com a resolução CoPGr 6018 de 2011

Orientador:

Prof. Dr. JOSÉ LAÉRCIO FAVARIN

Dissertação apresentada para obtenção do título de Mestra em Ciências. Área de concentração: Fitotecnia

Piracicaba

2019 
Dados Internacionais de Catalogação na Publicação DIVISÃO DE BIBLIOTECA - DIBD/ESALQ/USP

Reis, Marina Rodrigues dos

Redistribuição de nutrientes em razão da fenologia da frutificação do café arábica / Marina Rodrigues dos Reis - versão revisada de acordo com a resolução CoPGr 6018 de 2011- Piracicaba, 2019.

$45 \mathrm{p}$.

Dissertação (Mestrado) - USP/Escola Superior de Agricultura "Luiz de Queiroz".

1. Coffea arabica L. 2. Metodologia para avaliar redistribuição 3. Fonte - dreno 4. Retranslocação de nutrientes I. Título 
Aos meus pais João e Olinda, e aos meus irmãos Mariana e Cristiano, os quais sempre me apoiaram e são os maiores merecedores dessa conquista.

Dedico 


\section{AGRADECIMENTOS}

Gratidão é a virtude de quem reconhece em Deus e no outro o valor que ele tem e o que ela faz sem exigir nada em troca... Quem sabe agradecer está apto a crescer (CECILIA SFALSIN)

- Agradeço a Deus pelo dom da vida, e por me dar forças para seguir em frente em buscas de meus sonhos.

- Agradeço a Coordenação de Aperfeiçoamento de Pessoal de Nível Superior - Brasil (CAPES), pelo apoio financeiro para a realização deste trabalho - Código de financiamento 001;

- Aos meus pais João e Olinda, e aos meus irmãos Mariana e Cristiano, pelo apoio e amor. Vocês são a minha base, e se cheguei até aqui foi por vocês,

- Ao meu orientador Dr. José Laércio Favarin, pela dedição e ensinamentos prestados, proporcionando o meu crescimento profissional e pessoal,

- Ao Dr. Evandro Binotto Fagan e ao Dr. Luís Henrique Soares pelos ensinamentos, e pelo incentivo a busca por novos conhecimentos.

- A Escola Superior de Agricultura "Luiz de Queiroz" e ao Programa de Pós Graduação em Fitotecnia pela oportunidade.

- A fazenda São João por fornecer a área para a condução do experimento,

- Aos amigos do Núcleo de Pesquisa em Fisiologia e Estresse de Plantas (NUFEP), em especial a Isabella Sabrina, Leandra Larissa, Leidyanne Godinho, Rafael Goncalves, Jerssica Nogueira, Saulo Jomaa, Gustavo Cearence, José Gabriel, Layane Laura, Henrique Carneiro, Bruno Carvalho, Pedro Henrique, Felipe Antônio, Aurélio Carneiro, Izabel Cristina, Walquíria Fernanda e Ellen Mayara.

- Ao colegas do Laboratório Multiusuário pelo acolhimento, agradeço em especial ao Neto e ao Edson.

- Aos amigos que acompanharam a realização desse sonho, Letícia Matos, Sinara Alves e Bruno Silva.

- Ao Márcio pelo auxilio na condução do experimento, e realização da estatística, e à Laís Teles de Souza pelas dicas para a instalação do ensaio.

- Ao meu namorado Guilherme pelo carinho e amor e à sua familia pelo acolhimento e palavras de incentivo.

- As secretárias da pós-graduação, em especial à Luciane, por toda ajuda prestada.

- Enfim, agradeço a todos aqueles que contribuíram na realização deste trabalho, que vocês possam alcançar todos os objetivos com muito sucesso! 
"O conhecimento serve para encantar pessoas, não para humilhá-las". 
SUMÁRIO

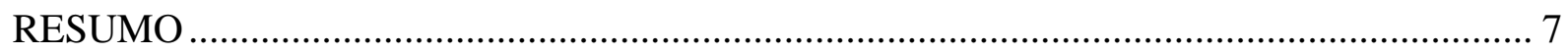

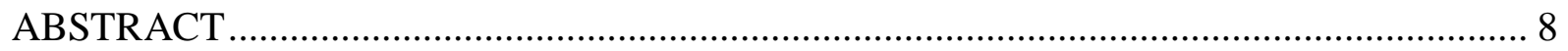

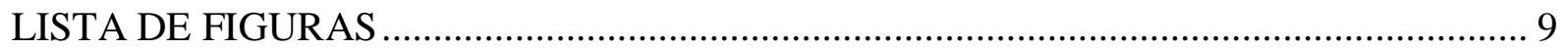

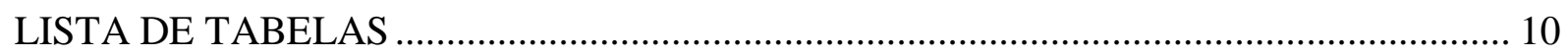

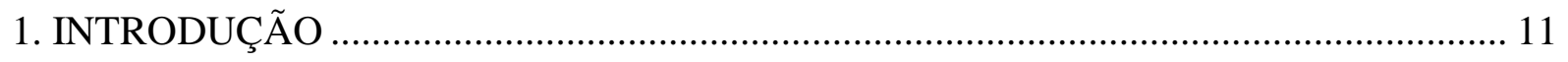

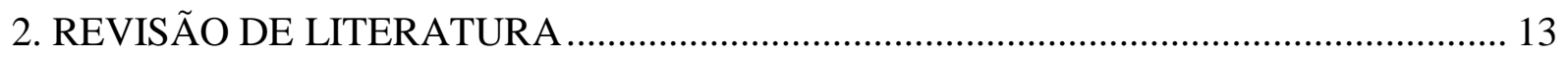

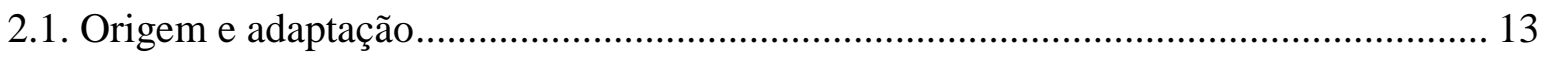

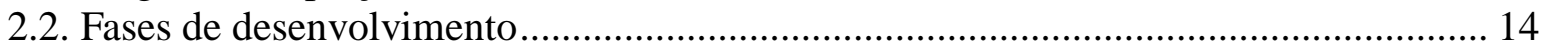

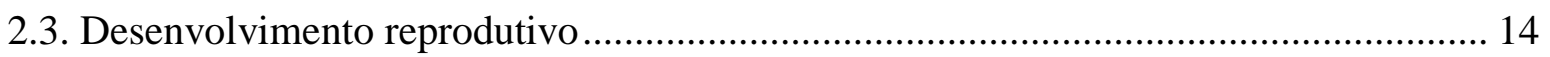

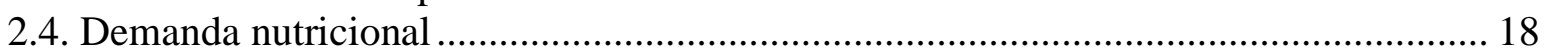

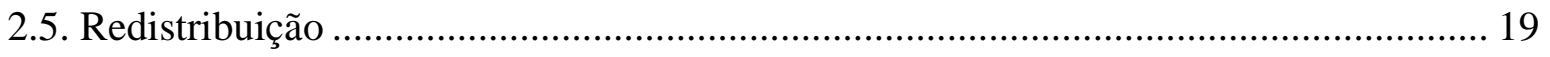

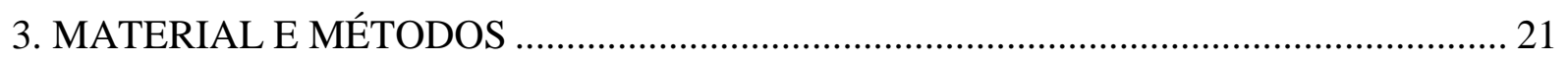

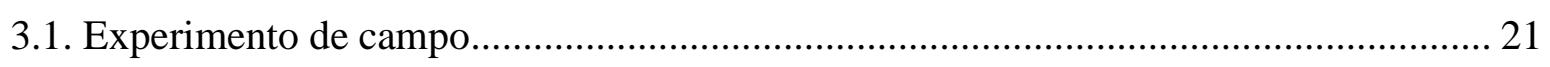

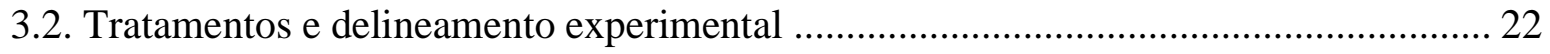

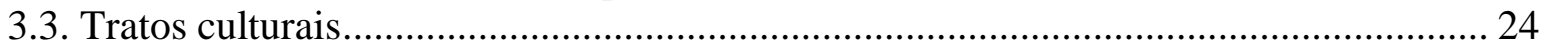

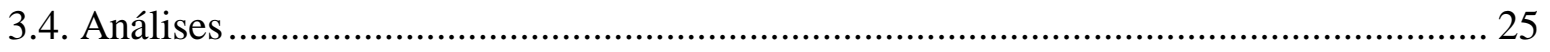

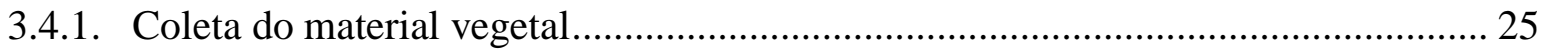

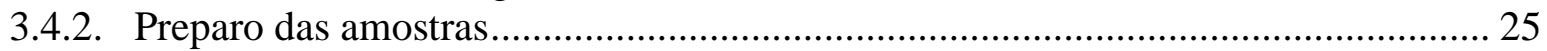

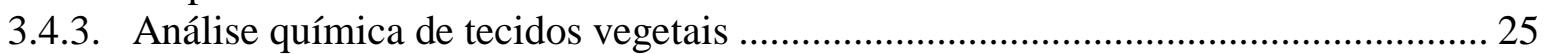

3.5. Avaliação da redistribuição (remobilização ou retranslocação) .................................. 25

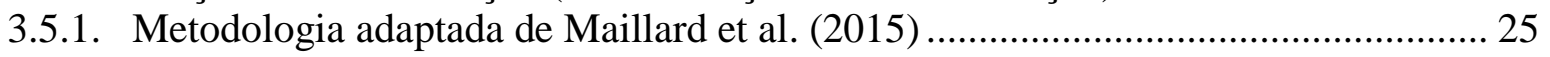

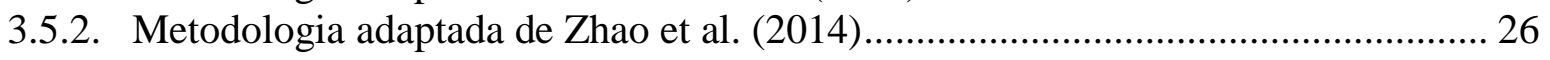

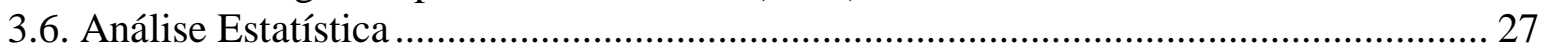

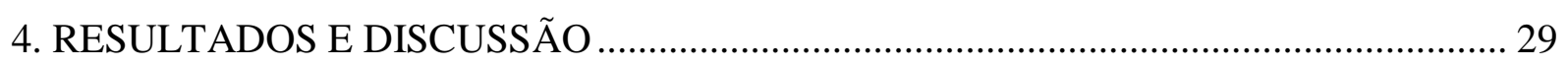

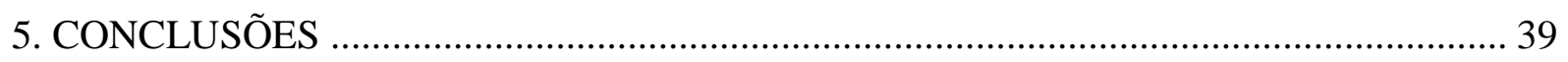

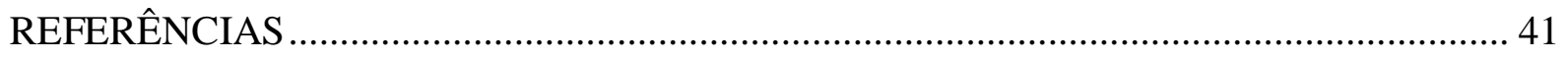




\section{RESUMO}

\section{Redistribuição de nutrientes em razão da fenologia da frutificação do café arábica}

O café é uma planta de crescimento contínuo. A cada novo ciclo vegetativo novos órgãos são formados e completa o crescimento dos órgãos existentes. As folhas presentes nos nós com frutos são fontes de fotoassimilados e de parte de nutrientes, por meio da redistribuição, durante a frutificação. A redistribuição é influenciada por vários fatores, entre os quais a carga de frutos e o estádio fenológico, a qual é incorretamente avaliada pela variação da concentração de nutriente no $3^{\circ}$ e/ou $4^{\circ}$ pares de folhas de café. Esse processo deve ser avaliado nas folhas maduras (folhas velhas) associadas aos nós com frutos, pois são as folhas fontes. Esta pesquisa foi realizada com o objetivo de avaliar duas metodologias para quantificar a redistribuição, identificar a fase da frutificação que o processo é significativo e, ainda, se a carga de frutos interfere na redistribuição. O trabalho foi realizado na fazenda São João, em Presidente Olegário - MG. Foram simuladas quatro cargas de frutos $(0 \%, 30 \%, 60 \%$ e $100 \%)$ entre fases fenológicas : chumbinho $(\mathrm{CH})$ - expansão (EX), expansão (EX) granação (GR), granação (GR) - maturação (MT) e chumbinho (CH) - maturação (MT). A redistribuição dos nutrientes $(\mathrm{N}, \mathrm{P}, \mathrm{K}, \mathrm{Mg}$ e $\mathrm{Zn}$ ) foi calculado com base na metodologia de Maillard e Zhao. As maiores redistribuições de N, P, K, Mg e Zn para a metodologia de Maillard et al. (2015) ocorreram entre as fases GR-MT; enquanto para a metodologia de Zhao et al. (2014) a maior redistribuição de $\mathrm{N}$ se deu entre as fases GR-MT, $\mathrm{K}, \mathrm{Mg}$ e $\mathrm{Zn}$ entre as fases CH-EX e de P entre EXGR. Para carga de frutos, a maior redistribuição de N, P, K, Mg ocorreu na ausência de frutos e Zn com $100 \%$ dos frutos presentes (metodologia Maillard), enquanto para a metodologia de Zhao a redistribuição de N e K foi maior na presença de 100\% dos frutos; P e Mg na carga de $60 \%$ de frutos e Zn quando havia 30\% de frutos nas plantas. As cargas pendentes de frutos e as fases de frutificação influenciaram na redistribuição dos nutrientes. O nutriente mais redistribuído foi o $\mathrm{K}$ e a maior fase de redistribuição ocorreu entre o periodo de granação e maturação. Das metodologias avaliadas no ensaio, recomenda-se o uso da metodologia de Maillard.

Palavras-chave: Coffea arabica L., Metodologia para avaliar redistribuição, Fonte - dreno, Retranslocação de nutrientes 
ABSTRACT

\section{Redistribution of nutrients due to the phenology of arabica coffee fruiting}

Coffee is a plant of continuous growth. With each new vegetative cycle new organs are formed and complete the growth of existing organs The leaves present in the nodes with fruits are sources of photoassimilates and part of nutrients, through the redistribution, during the fruiting. Redistribution is influenced by several factors, including fruit load and phenological stage, which is incorrectly assessed by the variation of nutrient concentration in the 3rd and / or 4th pairs of coffee leaves. This process must be evaluated in the mature leaves (old leaves) associated to the nodes with fruits, since they are the source leaves. This research was carried out with the objective of evaluating two methodologies to quantify the redistribution, to identify the fruiting phase that the process is significant and also, if the fruit load interferes with the redistribution. The work was carried out at Fazenda São João, in Presidente Olegário - MG. Four fruit loads (0\%, 30\%, 60\% and 100\%) were simulated between phenological phases: small green $(\mathrm{CH})$ - expansion $(\mathrm{EX})$, expansion $(\mathrm{EX})$ - seedfilling (GR), seed-filling (GR) - maturation (MT) and small green (CH) - maturation (MT). Redistribution of nutrients $(\mathrm{N}, \mathrm{P}, \mathrm{K}, \mathrm{Mg}$ and $\mathrm{Zn}$ ) was calculated based on the methodology of Maillard and Zhao. The largest redistributions of $\mathrm{N}, \mathrm{P}, \mathrm{K}, \mathrm{Mg}$ and $\mathrm{Zn}$ for the methodology of Maillard occurred between the GR-MT phases; while for the methodology of Zhao the greatest N redistribution occurred between the GR-MT, $\mathrm{K}, \mathrm{Mg}$ and $\mathrm{Zn}$ phases between the $\mathrm{CH}$-EX and P phases between EX-GR. For the fruit load, the highest redistribution of N, P and Mg occurred in the absence of fruits and $\mathrm{Zn}$ with $100 \%$ of the fruits present (Maillard), while for the methodology of Zhao the redistribution of $\mathrm{N}$ and $\mathrm{K}$ was greater in the presence of $100 \%$ of the fruits; $\mathrm{P}$ and $\mathrm{Mg}$ at $60 \%$ fruit load and $\mathrm{Zn}$ when there were $30 \%$ fruits in the plants. Pending fruit loads and fruiting phases influenced nutrient redistribution. The most redistributed nutrient was $\mathrm{K}$ and the largest redistribution phase occurred between the period of granation and maturation. Of the methodologies evaluated in the essay, the use of Maillard's methodology is recommended.

Keywords: Coffea arabica L., Methodology for assess redistribution, Source - sink, Nutrient retranslocation 


\section{LISTA DE FIGURAS}

Figura 1. Mapa geográfico da áfrica destacando a localização da etiópia e do congo em relação à linha do equador, países de origem do café arábica e conilon, respectivamente.

Figura 2. Esquematização das fases fenológicas do cafeeiro arábica, durante 24 meses, nas condições climáticas tropicais do brasil (CAMARGO; CAMARGO, 2001).

Figura 3. Estádios da floração e formação dos frutos de cafeeiro (RENA et al., 1986). ..................................16

Figura 4. Dados climáticos da área experimental, durante o periodo de realização do ensaio............................21

Figura 5. Esquema da separação da parte produtiva da parte vegetativa em cada ramo de café .........................24

Figura 6. Produtos utilizados para manejo da área experimental............................................................24

Figura 7. Identificação das folhas associadas aos nós com frutos coletadas para determinar a massa de matéria seca (MS)

Figura 8. Redistribuição de nitrogênio em plantas de café pelo método de Maillard (A) e pelo método de Zhao (B). *Letras maiúsculas se referem à comparação entre cada fase de frutificação, dentro de cada carga de frutos, enquanto, letras minúsculas se referem à comparação entre as cargas de frutos dentro de cada fase de frutificação.

Figura 9. Redistribuição de fósforo em plantas de café pelo método de Maillard (A) e pelo método de Zhao (B). *Letras maiúsculas se referem à comparação entre cada fase de frutificação, dentro de cada carga de frutos, enquanto, letras minúsculas se referem à comparação entre as cargas de frutos dentro de cada fase de frutificação.

Figura 10. Redistribuição de potássio em plantas de café pelo método de Maillard (A) e pelo método de Zhao (B). *Letras maiúsculas se referem à comparação entre cada fase de frutificação, dentro de cada carga de frutos, enquanto, letras minúsculas se referem à comparação entre as cargas de frutos dentro de cada fase de frutificação.

Figura 11. Redistribuição de magnésio em plantas de café pelo método de Maillard (A) e pelo método de Zhao (B). *Letras maiúsculas se referem à comparação entre cada fase de frutificação, dentro de cada carga de frutos, enquanto, letras minúsculas se referem à comparação entre as cargas de frutos dentro de cada fase de frutificação.

Figura 12. Redistribuição de zinco em plantas de café pelo método de Maillard (A) e pelo método de Zhao (B). *Letras maiúsculas se referem à comparação entre cada fase de frutificação, dentro de cada carga de frutos, enquanto, letras minúsculas se referem à comparação entre as cargas de frutos dentro de cada fase de frutificação.

Figura 13. Concentração de $\mathrm{N}$ nas folhas velhas (A) e folhas novas (B); de P nas folhas velhas (C) e folhas novas (D) e de $\mathrm{K}$ nas folhas velhas (E) e folhas novas (F).

Figura 14. Concentração de $\mathrm{Mg}$ nas folhas velhas (A) e folhas novas (B); de $\mathrm{Zn}$ nas folhas velhas (C) e folhas novas (D)

Figura 15. Concentração de N (A), P (B), K (C), Mg (D) e Zn (E) nos frutos de café. 


\section{LISTA DE TABELAS}

Tabela 1. Resultado da análise da fertilidade do solo, camadas de $0-20 \mathrm{~cm}$ e de $20-40 \mathrm{~cm}$.........................22

Tabela 2. Tratamentos - 4 cargas de frutos x 4 estádios fenológicos ..............................................................23

Tabela 3. Redistribuição de N, P, K, Mg e Zn, por hectare, pelas metodologia de Maillard e Zhao....................37 


\section{INTRODUÇÃO}

O café (Coffea arabica L.) é uma planta de crescimento contínuo, na qual a fase juvenil dura, em média, 30 meses. A partir de então a vegetação e a reprodução se repetem ao mesmo tempo, e é preciso atender as duas demandas de nutrientes minerais do cafeeiro. A força dreno da frutificação varia com a carga de frutos e a fenologia, e em geral é superior à força dreno da vegetação. A medida que os frutos se desenvolvem, há redistribuição de nutrientes das folhas associadas aos mesmos, no mesmo nó do ramo plagiotrópico.

A redistribuição, remobilização ou retranslocação ocorrem via floema, e são mais significativa para os elementos móveis. Este processo é biologicamente uma forma de a planta aproveitar as reservas minerais presentes nas folhas adultas. Em outras palavras, a remobilização é uma fonte de nutrientes, que se for muito drástica poderá acelerar a senescência das folhas fotossinteticamente ativas (folhas-fonte). Antecipar a perda destas folhas prejudicará o enchimento dos frutos, pois as mesmas produzem mais substâncias orgânicas do que consomem, cujo excedente é transportado aos frutos (drenos), onde a produção de fotoassimilados não é suficiente para suprir a sua demanda (MELOTTO, 1987; VAAST et al., 2005; LEMOINE et al., 2013; MOSCARDINI, 2017). A planta transfere também parte dos nutrientes móveis das folhas adultas (fontes) para os frutos, antes do fim da senescência (DISTELFELD, 2014; MAILLARD et al., 2015).

As folhas associadas aos nós com frutos são consideradas folhas adultas ou maduras, as quais a partir de determinada fase da frutificação, ainda desconhecida em café, fornecem parte dos nutrientes contidos nos frutos. A quantidade de nutrientes das folhas transferida para os frutos varia com a espécie, com a fenologia, a situação nutricional e a idade da planta (LIMA et al., 2011). Os minerais presentes nas folhas adultas vieram do solo e/ou da fertilização feita em anos anteriores. Conhecer até quando se dá a retranslocação é importante para orientar o planejamento da fertilização, fato importante, pois a transferência de nutrientes é maior em plantas deficientes (LIMA FILHO \& MALAVOLTA, 2003).

A remobilização de nutrientes está intimamente ligada à senescência e alguns trabalhos foram realizados para analisar esta redistribuição de nutrientes em café. Porém, na verdade, foi realizado o acompanhamento nutricional do terceiro/quarto par de folhas. Estas folhas são indicativas do estado nutricional da lavoura, mas não são adequadas para quantificar a redistribuição de nutrientes, pois estão localizadas no final do ramo plagiotrópico, relativamente distante dos frutos. Além disso, devido ao crescimento dos ramos, o terceiro/quarto par de folhas, será uma folha recém madura e, biologicamente, espera-se que os elementos móveis sejam preferencialmente translocados para os frutos. Não é razoável que os mesmos desloquem às folhas em formação (terceiro/quarto par folhas) na parte final do ramo e, posteriormente, quando maduras, destas para os frutos. Isto pode acontecer com os nutrientes provenientes do solo.

Para avaliar a redistribuição de nutrientes, o mais adequado é utilizar as folhas maduras (folhas velhas), pois estas estão localizadas próximo aos frutos e, no início da resdistribuição de minerais, podem contribuir com a demanda destes frutos, de acordo com o princípio fonte - dreno.

Portanto, a presente pesquisa teve por objetivo caracterizar a redistribuição de nitrogênio $(\mathrm{N})$, fósforo $(\mathrm{P})$, potássio $(\mathrm{K})$, magnésio $(\mathrm{Mg})$ e zinco $(\mathrm{Zn})$, entre duas fases subsequentes da frutificação, com base na diferença na concentração desses nutrientes nas folhas adultas associadas aos nós com frutos e no frutos em razão da carga pendente, em cafeeiro cultivado em campo, sem destruição de plantas, por meio de duas metodologias, identificando as fases e as cargas de maior redistribuição de nutrientes. 


\section{REVISÃO DE LITERATURA}

\subsection{Origem e adaptação}

O café arábica é uma planta de origem dos sub-bosques das florestas da Etiópia e Sul do Sudão, que se encontram em altitudes entre 1600 e $2800 \mathrm{~m}$ e latitudes variando de $6^{\circ}$ a $9^{\circ} \mathrm{N}$. Neste local o clima é caracterizado por uma estação seca que dura entre 2 e 4 meses, com o restante do ano úmido e com temperaturas amenas. Assim, as temperaturas variam entre 17 e $19^{\circ} \mathrm{C}$ nas épocas mais frias do ano e entre 22 e $26^{\circ} \mathrm{C}$ nos meses mais quentes (DaMATTA; RAMALHO, 2006; REIS; CUNHA, 2010). No entanto, o café conilon (Coffea canephora Pierre \& Froehner) se origina de sub-bosques densos das florestas Equatoriais do Congo, se estendendo até a Uganda. Nesta região o clima é caracterizado por altitudes que variam do nível do mar até $1200 \mathrm{~m}$, com temperaturas médias entre 24 e $26^{\circ} \mathrm{C}$ ao longo do ano, precipitação superior a $2000 \mathrm{~mm}$ ao ano, distribuída ao longo de nove meses (DaMATTA; RAMALHO, 2006; FERRÃO et al., 2007) (Figura 1).

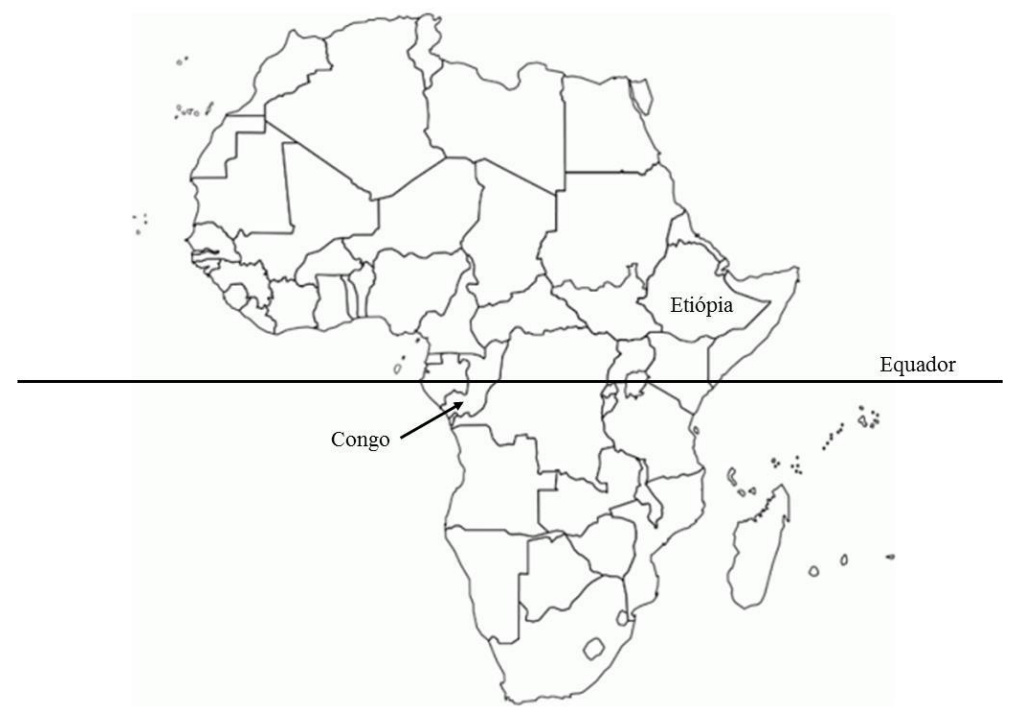

Figura 1. Mapa geográfico da África destacando a localização da Etiópia e do Congo em relação à Linha do Equador, países de origem do café arábica e conilon, respectivamente.

Estas características são importantes porque auxiliam no entendimento da adaptabilidade do cafeeiro às condições brasileiras. Como exemplo, o café arábica tem sua melhor adaptação nas regiões de alta altitude com temperaturas amenas, localizadas principalmente nos estados de Minas Gerais e São Paulo, enquanto que o café conilon, devido à exigência de maiores temperaturas se adapta melhor nas regiões de menor altitude do Espirito Santo, extremo sul da Bahia e Rondônia.

Para o cafeeiro arábica, temperatura de $18^{\circ} \mathrm{C}$ durante a noite e $22 \mathrm{C}$ durante o dia são as ideiais para o desenvolvimento. Extremos de $15^{\circ} \mathrm{C}$ à noite e entre 25 e $30^{\circ} \mathrm{C}$ durante o dia são tolerados, embora estas últimas reduzam a fotossíntese das plantas. Acima de $30{ }^{\circ} \mathrm{C}$ pode ocorrer clorose das folhas e abortamento das flores (DESCROIX; SNOECK, 2004).

Naturalmente, as plantas de café são adaptadas a condições de sombreamento. No entanto, quase todas as cultivares utilizadas na atualidade são descendentes de plantas que foram introduzidas na Arábia, onde foram 
cultivadas por mais de mil anos em ambientes relativamente secos e sem sombreamento, antes da introdução na Ásia e na América Latina. Portanto, a maioria das cultivares possuem atributos fisiológicos que permitem baixo nível de dano sob condições de cultivo em plena luz. Além disso, o florescimento, a brotação das gemas e o crescimento vegetativo são estimulados sob condições de plena luz. Assim, o cafeeiro apresenta maior produtividade quando cultivado sem sombreamento (DaMATTA et al., 2007). Embora as cultivares de café utilizadas na atualidade tenham sido melhoradas e selecionadas sob condições de plena luz (DaMATTA et al., 2007), ainda é possível observar no campo a escaldadura. Este dano é caracterizado pela clorose e, às vezes, necrose dos tecidos, quando há alta luminosidade incidente de forma perpendicular sob as folhas.

\subsection{Fases de desenvolvimento}

O desenvolvimento das plantas de cafeeiro pode ser divido em três fases sendo (i) germinação e emergência, (ii) crescimento vegetativo e (iii) crescimento reprodutivo. A fase de germinação e emergência é caracterizada pela embebição, desenvolvimento do embrião e emergência da plântula, formando uma nova planta. A partir da emergência, as plântulas iniciam o desenvolvimento do sistema radicular e o crescimento vegetativo da parte aérea, até atingirem entre seis a oito pares de folhas. Posteriormente, continua o desenvolvimento do ramo ortotrópico (vertical) e dos ramos plagiotrópicos (laterais e reprodutivos) por um período entre 24 e 36 meses. Neste intervalo, se inicia a diferenciação das gemas vegetativas em reprodutivas, o que caracteriza o início da fase reprodutiva. Concomitantemente, o desenvolvimento vegetativo continua. O ciclo fenológico acontece durante dois anos, onde no primeiro ano ocorre o crescimento vegetativo, a formação e diferenciação das gemas e no segundo acontece a florada e o desenvolvimento dos frutos (Figura 2) (CAMARGO; CAMARGO, 2001).

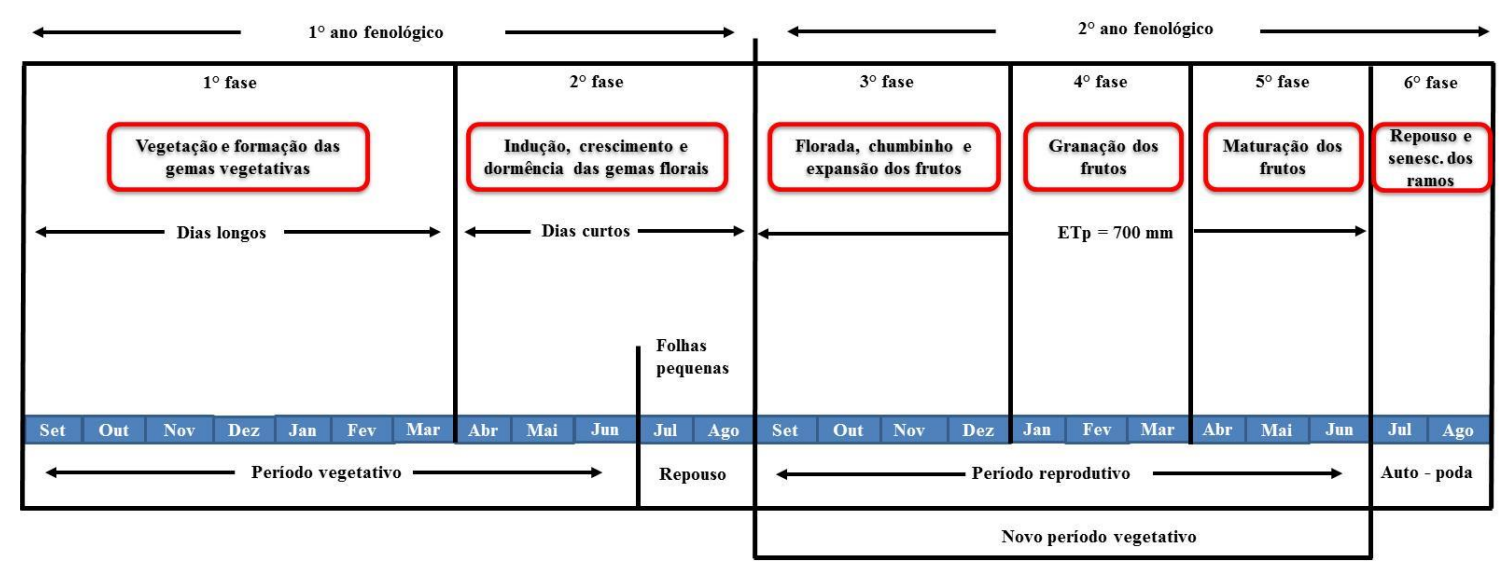

Figura 2. Esquematização das fases fenológicas do cafeeiro arábica, durante 24 meses, nas condições climáticas tropicais do Brasil (CAMARGO; CAMARGO, 2001).

\subsection{Desenvolvimento reprodutivo}

O desenvolvimento reprodutivo inicia com a indução do florescimento e a evocação do meristema, que passa irreversivelmente de vegetativo para reprodutivo. Durante este período ocorre a diferenciação das gemas seriadas presentes nas axilas das folhas dos ramos plagiotrópicos (CAMARGO; CAMARGO, 2001), que é 
dependente do estímulo floral. Essa transição floral (evocação), que culmina na transformação da gema vegetativa em reprodutiva, compreende vários eventos de natureza morfológica, fisiológica e bioquímica (RENA et al., 1986; CARVALHO, 2008).

As gemas seriadas do ramo plagiotrópico podem dar origem a folhas, ramos de segunda ordem ou botões florais. No entanto, o ideal é que estas se diferenciem apenas em estruturas florais. Além disso, em torno de 20 a $30 \%$ das gemas permanecem indiferenciadas para ramificações futuras, enquanto o adequado seria que estas se tornassem flores. No entanto, pouco se sabe sobre os processos envolvidos na indução e diferenciação das gemas do cafeeiro (MAJEROWICZ; SÖNDAHL, 2005). Vários trabalhos citam que fatores ambientais como radiação, temperatura e disponibilidade de água podem atuar controlando estes processos (CAMAYO-VÉLEZ et al., 2003; MAJEROWICZ; SÖNDAHL, 2005; QUEIROZ-VOLTAN et al., 2011). Além disso, a carga de frutos no ramo também tem sido relatada como um dos fatores que determinarão a diferenciação das gemas, devido à modulação da disponibilidade de fotoassimilados (QUEIROZ-VOLTAN et al., 2011). Nos trabalhos realizados por Majerowicz; Söndahl (2005) e Queiroz-Voltan et al. (2011) foi observado que quando os ramos apresentavam baixa carga de frutos, houve antecipação da diferenciação das gemas para março/abril, enquanto nos ramos com elevada carga a diferenciação ocorreu em maio.

Como apresentado na Figura 2, as gemas que originarão frutos iniciam seu desenvolvimento muito antes que isso seja visível no campo. Entre os meses de setembro e março ocorre o desenvolvimento vegetativo do ramo plagiotrópico, onde estão sendo formadas as gemas. Aproximadamente entre os meses de fevereiro e março estas gemas recebem a indução ou iniciação para diferenciação floral (CAMARGO; CAMARGO, 2001). Geralmente, três a quatro gemas de inflorescências formam-se nas axilas das folhas e com quatro a cinco flores em cada inflorescência (QUEIROZ-VOLTAN et al., 2011). Tem sido relatado que as condições ideais para a indução floral são a ausência de déficit hídrico severo e a ocorrência de dias quentes e noites frescas (a faixa de 18 a $22{ }^{\circ} \mathrm{C}$ é adequado para o cafeeiro) (CARVALHO, 2008). Desta forma, é notável que o desenvolvimento dos ramos e, consequentemente, das gemas que se tornarão produtivas na safra seguintes ocorrem simultaneamente com a formação e os enchimentos dos frutos da safra atual. Portanto, há uma competição por fotoassimilados entre o crescimento vegetativo e reprodutivo, o que é prejudicial, principalmente ao crescimento vegetativo. Esta característica associada às variações climáticas e ao fato de a planta de café abortar poucos frutos devido à ausência de uma zona de abscisão bem definida (BRANDÃO et al., 2016), explica o efeito chamado bienalidade do cafeeiro, que consiste em um ano de alta seguido por outro de baixa produtividade.

Depois de, aproximadamente, dois meses de crescimento dos primórdios florais, estes atingem tamanho entre 4 a 6 mm e entram em dormência (CARVALHO, 2008; REIS; CUNHA, 2010). Este período normalmente coincide com aos meses de julho a agosto (Figura 2), quando o adequado é que ocorra pequeno deficit hídrico e temperaturas amenas $\left(16\right.$ a $\left.18{ }^{\circ} \mathrm{C}\right)$. Nesta fase os primórdios florais são caracterizados por uma coloração amarelopálida, presença de alta concentração de ABA e restrita ligação vascular. Cabe ressaltar que até o fim da fase de dormência, mesma que as gemas estejam em desenvolvimento, não é possível visualizá-las no campo. Este período de dormência é importante para a produção do cafeeiro, principalmente para que ocorra a uniformização da formação das gemas, visto que estas foram formadas de acordo com o crescimento do ramo entre os meses de setembro a fevereiro/março. Desta forma, sem a restrição hídrica, os botões florais crescem de forma contínua, o que resulta em floradas sucessivas, já que a iniciação floral dos primórdios florais se dá por períodos relativamente extensos. Além disso, caso haja ocorrência de chuvas durante este período irá ocorrer má uniformidade da floração, visto que em uma mesma lavoura há botões florais em várias fases de formação (CARVALHO, 2008). Isto repercute 
em desuniformidade na formação dos frutos, o que causa falta de sincronismo da maturação e, consequentemente na colheita da lavoura (DaMATTA et al., 2007).

Em estudo realizado por Queiroz-Voltan et al. (2011) os autores observaram no ano de alta carga de frutos entre junho e agosto e no ano de carga baixa de maio a agosto, em uma mesma inflorescência diferentes estádios de desenvolvimento floral. Isso porque as gemas florais se diferenciavam, uma a uma, em tempos diferentes, na mesma inflorescência. Essas diferenças ocorriam também entre inflorescências de uma mesma axila foliar, entre diferentes posições nos nós de um ramo, entre ramos de uma planta e entre plantas. Por isso, na fase de maturação do fruto, são observados diferentes estádios (verde, verde-cana, cereja, passa e seco) na mesma axila foliar, ramos e plantas. Para uniformizar a floração seria necessário que os botões mais maduros permanecessem em dormência até que todos os botões mais jovens atingissem a diferenciação de seus verticilos e, na fase da antese, após as chuvas, todas as flores abrissem ao mesmo tempo, ou seja, um controle da floração entre o terceiro e quinto estádio.

Assim que ocorrem as primeiras chuvas, normalmente em meados de setembro, é observada redução na concentração de $\mathrm{ABA}$ na gema e reestabelecimento da conexão xilemática, permitindo que as gemas iniciem a reidratação (Figura 3). Neste período é que se torna possível a visualização das gemas na axila das folhas. Embora ainda não existam informações concretas, é especulado que esta fase sofra forte modulação hormonal envolvendo, principalmente, $\mathrm{ABA}$, auxina e giberelina. $\mathrm{O}$ ABA é conhecido como o hormônio que mantém a dormência das gemas. Possivelmente, este efeito inibe o acúmulo de auxina e giberelinas nas gemas, o que reduz a conexão xilemática e o desenvolvimento. Quando a água se torna disponível, a concentração de ABA reduz, e possibilita a auxina e a giberelina induzirem a divisão e expansão celular, reestabelecendo a conexão com os vasos condutores, necessária à reidratação da gema.

Após o intumescimento das gemas, os botões florais crescem durante 8 a 16 dias, chegando a atingir, aproximadamente, $12 \mathrm{~mm}$, devido ao intenso acúmulo de água e carboidratos. Esta fase, no campo é conhecida como abotoamento. Após este período ocorre a antese (abertura da flor), quando a corola alcança aproximadamente $21 \mathrm{~mm}$ de comprimento. Geralmente, a abertura das flores acontece entre 8 a 12 dias após as chuvas de florada ou reestabelecimento da irrigação (pelo menos 8 a $10 \mathrm{~mm}$ ) (Figura 3) (CARVALHO, 2008), sendo o florescimento rápido para maiores temperaturas e o mais demorado para menor temperatura (RENA et al., 1986). De forma simultânea ao processo de liberação da dormência das gemas e à antese, o crescimento vegetativo dos ramos é retomado.

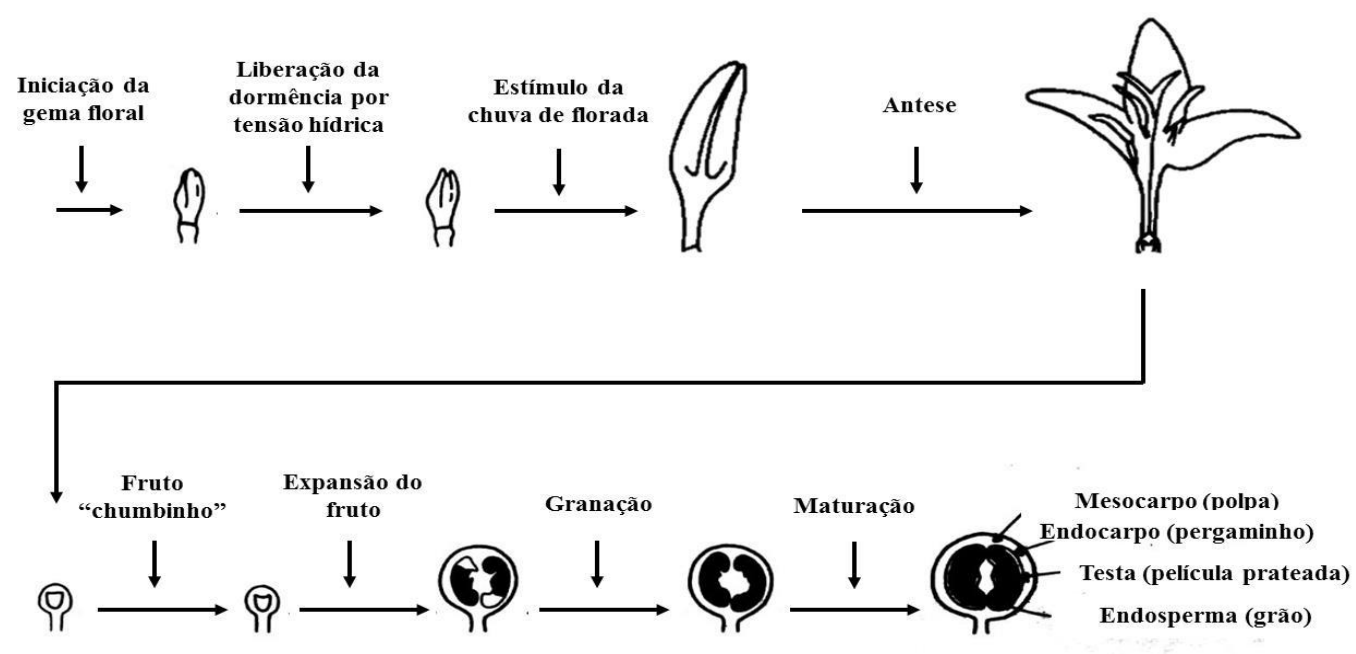

Figura 3. Estádios da floração e formação dos frutos de cafeeiro (RENA et al., 1986). 
Estudos mostram que o desenvolvimento normal do botão floral e a antese dependem fortemente do número de folhas por nó, número total de folhas e do teor de amido no ramo (GOPAL et al., 1975). Estes resultados realçam a importância da produção de fotoassimilados após a retomada do crescimento. Além disso, mostra o quanto é importante a manutenção da área foliar das plantas durante a fase de dormência, ou seja, entre a colheita e o florescimento, visto que a fotossíntese corrente foi mais importante do que outras fontes de fotoassimilados para o crescimento das flores (BARROS et al., 1982).

A partir do florescimento, os frutos iniciam a fase de crescimento, os quais passam pelas fases de chumbinho, expansão, granação e maturação. O fruto permanece na fase chumbinho por entre seis a dez semanas, sendo que neste período não acontece crescimento do fruto, embora estes apresentem elevada taxa respiratória e intensa divisão celular, mas sem expansão. Logo após se inicia a fase de expansão dos frutos, que dura em torno de 10 semanas (DaMATTA et al., 2007). Este período é marcado por incremento na concentração de citocininas e giberelinas e intenso acúmulo de matéria fresca, o que repercute no aumento da demanda de nutrientes pelas plantas. Além disso, há intensa demanda de fotoassimilados, já que os frutos apresentam força dreno em torno de 4 a 5 vezes maior que o crescimento vegetativo (RENA et al., 1986). Além da competição entre os frutos e o crescimento vegetativo, pode ocorrer limitação da distribuição de fotoassimilados para as raízes (BRAGANÇA, 2005).

Entre a expansão e granação, durante aproximadamente duas semanas, segue a fase de crescimento suspenso, onde os frutos ainda acumulam matéria fresca lentamente, mas não aumentam de tamanho. Durante a fase de granação, ocorre intenso acúmulo de massa de matéria seca, depositada principalmente nas sementes. Neste período, a elevada demanda de nutrientes e fotoassimilados pelos frutos são mantidas. De acordo com Cannell (1985), nas fases finais de crescimento os frutos acumulam até 95\% do potássio, fósforo e nitrogênio. Ao fim das etapas de crescimento, ocorre a maturação do fruto, onde o pericarpo aumenta de tamanho, acumula massa de matéria fresca e seca e os frutos mudam de cor, para vermelhos ou amarelos, conforme a cultivar (DaMATTA et al., 2007).

Durante as fases de desenvolvimento dos frutos estes também são considerados importantes fontes de fotoassimilados para o seu enchimento. Neste período, os frutos são verdes, contem estômatos e podem representar entre 20 e 30\% da área fotossintética da planta de cafeeiro (CANNELL,1985; DaMATTA et al., 2007). Martinez et al. (1996) mostrou que a $600 \mu \mathrm{mol}$ fótons $\mathrm{m}^{-2} \mathrm{~s}^{-1}$, a atividade fotossintética dos frutos em ramos destacados das plantas pode compensar as perdas pela respiração, além de sobrar uma pequena quantidade de $\mathrm{CO}_{2}$ que é transformado em massa de matéria seca.

Um dos fatores que determinam a qualidade da bebida é o tempo de maturação do fruto. Na etapa de maturação ocorre a translocação de compostos fenólicos da semente para as camadas superficiais (DENTAN, 1985), entre eles destaca-se a migração dos ácidos clorogênicos, que apresentam uma relação direta com a qualidade de bebida. Alguns autores ressaltaram que um dos motivos do aumento da qualidade em grãos com maior tempo de formação é devido a alterações bioquímicas envolvendo o ácido clorogênico (OHIOKPEHAI et al., 1982). Acreditase que no final da maturação de frutos o ácido clorogênico seja translocado da semente para a periferia do fruto, como uma ação de desestímulo a ingestão precoce por parte de animais ou proteção da semente ao ataque de microrganismos (CORTEZ, 2001; FAGAN et al., 2011). 


\subsection{Demanda nutricional}

A nutrição mineral de plantas está relacionada à maneira como as plantas obtém os elementos minerais e como estes funcionam no desenvolvimento (EPSTEIN; BLOOM, 2006). Entender sobre a nutrição de plantas, se faz necessário para o manejo adequado da cultura, além de compreender o papel dos nutrientes nos diversos mecanismos das plantas.

Cerca de 95\% da matéria seca vegetal, corresponde a carbono (C), oxigênio $(\mathrm{O})$ e hidrogênio $(\mathrm{H})$, os 5\% restantes corresponde aos minerais (FAQUIN, 2005). Os elementos fornecidos pelo solo podem ser de ocorrência natural ou pelo fornecimento de fertilizantes, via adubação. A adubação é realizada para atender a demanda da planta pelo nutriente para vegetar e frutificar, levando-se em consideração o que o solo tem a oferecer (MALAVOLTA, 2006).

O cafeeiro possui alta exigência nutricional para atendar as demandas de crescimento vegetativo e reprodutivo. De acordo com Corrêa et al. (1986), para as variedades Catuaí e Mundo Novo as maiores exigências nutricionais são entre 6 e 78 meses após o plantio. As demandas nutricionais do cafeeiro não variam de acordo com sua produção, pois em anos de baixa, a formação de novas folhas e ramos funcionam como drenos para as plantas (MALAVOLTA et al., 2002). Para Matiello (2010), cada saca de café produzida, o cafeeiro necessita de 6,2 kg de N; 0,6 kg de $\mathrm{P}_{2} \mathrm{O} 5 ; 5,9 \mathrm{~kg}$ de $\mathrm{K}_{2} \mathrm{O} ; 3,0 \mathrm{~kg}$ de $\mathrm{CaO} ; 1,9 \mathrm{~kg}$ de $\mathrm{MgO}$ e 0,3 $\mathrm{kg}$ de S. Desses valores totais, 2,6, 0,23 e 3,0 kg de N, P e K, nessa ordem, são necessários para produção de grãos.

A exigência nutricional do cafeeiro varia de acordo com a fenologia e disponibilidade hídrica. Como já supracitado o ciclo fenológico dessa cultura ocorre em dois anos; dessa maneira, numa mesma planta existem ramos vegetativos e ramos reprodutivos e o fornecimento de nutrientes deve atender as duas demandas - frutos mais o acréscimo vegetativo (NETO, 2009).

A florada inicia nas primeiras chuvas de primavera, seu desenvolvimento depende da atividade fisiológica do cafeeiro durante o período do inverno. Nesse período há um pequeno crescimento da parte vegetativa e as raízes acumulam compostos nitrogenados e reguladores vegetais que são transportados para a parte área onde são usados no desenvolvimento vegetal no início da primavera (AMARAL, 1991; MATTA et al., 1999; MALAVOLTA et al., 2002).

Posterior à florada, durante a formação dos frutos as exigências nutricionais são variáveis. De acordo com Mattielo (2005) a demanda de nutrientes durante a fase chumbinho é baixa, porém a medida que o desenvolvimento passa para as fases de expansão, granação e maturação a demanda por nutrientes é crescente. Isso se dá pelo fato de os frutos serem os drenos preferenciais das plantas.

Em razão da variação na exigência nutricional durante as fases de desenvolvimento se faz importante não só conhecer a dose do nutriente, mas também a fase de maior demanda. Para isso as curvas de respostas de nutrientes nas fases reprodutivas do cafeeiro são utilizadas para determinar as épocas de maior demanda de nutrientes bem como a dose adequada (LAVIOLA, 2007). Porém, as respostas obtidas nessas curvas não podem ser utilizadas de maneira generalizada, uma vez que a fenologia do cafeeiro sofrerá a influencia do ambiente, a qual pode ser maior ou menor de um local para o outro (LAVIOLA, 2007).

A nutrição mineral, na cultura do café, além de realizar a manutenção das plantas para que possam se desenvolver, produzindo nova vegetação e frutos, pode influenciar na qualidade da bebida (MARTINEZ et al., 2014). Em estudo realizado por Clemente (2010) o autor avaliou duas doses de N, verificou que na maior dose 
testada a concentração de cafeína na folha foi maior, a qual tem em sua composição quatro átomos de $\mathrm{N}$ na molécula (IKAN,1991).

Além do $\mathrm{N}$, outro importante nutriente que pode influenciar na qualidade dos grãos de café, e por sua vez, na qualidade da bebida é o K, este nutriente faz parte de inúmeros processos, como abertura e fechamento estomático, transporte de açúcar e ativação de enzimas, como a polifenoloxidase, enzima que oxida fenóis e está relacionada à qualidade de bebida (MARTINEZ et al., 2014). Silva, Nogueira e Guimarães (2002) verificaram que os componentes bioquímicos relacionados à qualidade do café, variaram de acordo com as doses de $\mathrm{K}$ utilizadas.

O Zn atua na síntese de proteínas, na síntese do aminoácido triptofano; este por sua vez, atua na síntese da auxina, hormônio relacionado a expansão celular, atua em enzimas no sistema antioxidante, como a superóxido dismutase e na produção de sementes. Na cultura do café, em trabalho realizado por Melo et al., (1999), plantas nutridas com zinco obtiveram maior porcentagem de grãos classificados em peneiras maiores.

\subsection{Redistribuição}

Inicialmente, pesquisadores que trabalhavam com translocação de nutrientes em plantas acreditavam que os nutrientes eram providos exclusivamente do solo. Em 1679, Malpigh demonstrou que a seiva bruta era modificada nas folhas através da ação da luz solar, e que essa mesma seiva era redistribuída para outras partes das plantas (VALARINI, 2005).

O movimento de um nutriente de um local de acúmulo para outro órgão qualquer é definido como redistribuição, onde o local de reserva é uma folha, ramo ou raiz, e recebem o nome de fonte, enquanto o outro órgão pode ser folhas, ramos ou raízes novas ou frutos e são classificados como dreno (MALAVOLTA, 2006).

Aa redistribuição dos nutrientes, ocorre no floema, das reservas para as zonas de crescimento, aérea ou radicular, simultaneamente com os fotoassimilados (BATAGLIA, 2001). As regiões de acúmulo podem estar entre dois drenos, uma folha nova em desenvolvimento, localizada acima, e um fruto, localizado abaixo. O movimento dos elementos minerais das folhas maduras para os ógãos novos em crescimento é uma atividade comum à aproximação do fim do ciclo de vida da planta (CAMARGO E MURAOKA, 2007).

As folhas novas utilizam assimilados das folhas mais velhas inferiores, além dos assimilados que elas mesmas produzem, dessa forma são drenos. Quando amadurecem, passam a serem apenas fontes para novas folhas em formação e para outros órgãos drenos, como os frutos.

As funções dos nutrientes são variáveis, podem ser constituintes metabólicos ou de estruturas, dessa forma a redistribuição varia de acordo com cada nutriente, podendo ser redistribuído em maior ou menor quantidade pelo floema (SFREDO e BORKET, 2004). Por isso, Malavolta (2006) classifica os nutrientes minerais, quanto a mobilidade no floema, da seguinte forma:

móveis: $\mathrm{N}, \mathrm{P}, \mathrm{K}, \mathrm{Mg}, \mathrm{Cl}$ e $\mathrm{Mo}$;

pouco móveis: S, Cu, Fe, Mn e Zn e

quase imóveis: Ca e B.

Em estudo realizado por Borin, Lana e Pereira (2010) sobre absorção, acúmulo e exportação de macronutrientes em milho doce, verificaram que a concentração de $\mathrm{N}$ e K nas folhas diminuía na fase de formação da espiga, e que 52 e 40\% da concentração total do nutriente na planta eram redistribuídos para a espiga, para N e K, respectivamente. 
Ao avaliar a absorção, repartição e redistribuição de P durante o enchimento de grãos no arroz, Julia et al. (2016) concluíram que após o florescimento, há pouca transferência direta de P absorvido para os grãos, ocorrendo a redistribuição do P que estava armazenado nos tecidos vegetativos.

Além da mobilidade no floema, em espécies perenes, a redistribuição varia de acordo com a espécie, a idade da planta, estádio fenológico, condições ambientais e práticas de manejo (LIMA et al., 2011). A concentração do elemento na folha pode aumentar ou diminuir de acordo com o desenvolvimento da planta, pois ocorre a translocação dos nutrientes das folhas para novos órgãos em desenvolvimento (GEORGE et al., 1989).

Estudos realizados em mangueiras verificou-se que as maiores concentrações de $\mathrm{N}, \mathrm{P}$ e $\mathrm{K}$ eram encontradas antes da floração; posteriormente, época de plena floração e frutificação os teores desses nutrientes diminuíram nas folhas (AVILAN, 1971).

Em plantas de café, durante a fase de desenvolvimento dos frutos há uma alta demanda de nutrientes; nesse período é observada uma queda no teor de nutrientes nas folhas, principalmente de macronutrientes, o que pode ocasionar a queda, comprometendo a produção da safra seguinte (BONNET, 1969). Além disso, a concentração de nutrientes nas folhas varia de acordo coma a produção da planta (MALAVOLTA, 1979).

Na pesquisa realizada por Laviola (2007), o autor avaliou a alocação de fotoassimilidados e nutrientes em folhas e frutos de cafeeiro, os resultados demonstraram que o acúmulo de macronutrientes no fruto foram na seguinte proporção: $\mathrm{K}>\mathrm{N}>\mathrm{Ca}>\mathrm{Mg}>\mathrm{S}>$ P. Alves et al., (2007) estudou a demanda de nutrientes pelas folhas e frutos do cafeeiro durante a fase reprodutiva, os autores concluíram que os frutos são fortes drenos de $\mathrm{N}$ e $\mathrm{K}$.

Para verificar a translocação lateral de N, P e K, (Franco (1983). trabalhou com plantas de café divididas em duas partes, em solos pobres do cerrado. Os elementos foram colocados em apenas um lado da raiz, e vinte e dois meses após adubação foi realizada análise foliar para verificar se havia translocação dos elementos. As folhas do lado que não recebeu o adubo apresentavam $68 \%$ de $\mathrm{K}, 52 \%$ de $\mathrm{P}$ e $45 \%$ de $\mathrm{N}$,

Em estudo realizado com a variedade Mundo Novo, verificou decréscimo de P nas folhas durante o desenvolvimento dos frutos do cafeeiro. Laviola et al. (2007) analisando a dinâmica de P e S em folhas, flores e frutos de cafeeiro em três níveis de adubação, concluiram que a concentração dos nutrientes nos tecidos vegetais, não só é influenciado pelo nível de adubação, mas também pela carga do fruto, que determina a distribuição dos nutrientes nas plantas de café. O mesmo autor, em outro trabalho, avaliou a dinâmica de Ca e $\mathrm{Mg}$ em folhas e frutos do cafeeiro e obteve o mesmo resultado, onde a carga de frutos nos ramos plagiotrópicos determina a distribuição dos elementos minerais na planta (CHAVES, 1982).

É importante ressaltar que o fornecimento de nutrientes para os frutos pode ocorrer via folhas, entretanto, não é a única via de fornecimento. Os nutrientes podem ser fornecidos aos frutos, via remobilização das folhas mais velhas, de outros órgãos das plantas, por meio do solo, ou ainda essas vias podem ocorrer de forma simultânea (VALARINI, 2005).

No que se refere a cultura do cafeeiro, as pesquisas realizadas com o intuito de avaliar a redistribuição de nutrientes utilizaram o terceiro/ quarto par de folhas (CATANI et al., 1965; BONNET, 1969; HIROCE, 1981; VALARINI et al., 2005, ALVES et al., 2007; LAVIOLA et al., 2007). Ressalte-se que o terceiro e/ou quarto pares foliares, localizados na parte final do ramo produtivo, a partir da sua inserção no caule, são folhas recém-maduras, relativamente distantes dos frutos, presentes na parte inicial do mesmo ramo. Essas folhas servem para o diagnóstico da situação nutricional da planta, mas não são indicadas para avaliar a redistribuição de nutrientes, pois teriam que retornar à base dos ramos onde estão os frutos, o que pode ocorer com os elementos provenientes do solo, porém, com base nos conceitos da relação fonte dreno, não é esperado. 


\section{MATERIAL E MÉTODOS}

\subsection{Experimento de campo}

O ensaio foi realizado de novembro de 2017 a junho de 2018, na fazenda São João, no município de Presidente Olegário - MG, Brasil (18³5’25” de latitude sul, 46²19’20” de longitude oeste e $1.045 \mathrm{~m}$ de altitude). O clima da região é do tipo tropical de altitude de acordo com a classificação de Koppen, com temperatura média no periodo do ensaio de $22{ }^{\circ} \mathrm{C}$, temperatura máxima de $31{ }^{\circ} \mathrm{C}$, mínima de $11,9{ }^{\circ} \mathrm{C}$, e $1.255,5 \mathrm{~mm}$ de precipitação pluvial (Figura 4). A cultivar utilizada foi Catuaí 144, com espaçamento de 3,8 m entre linhas e 0,55 m entre plantas, o que proporciona uma população de 4.784 plantas por hectare, com produção de 50 sacas ha- $^{-1}$.

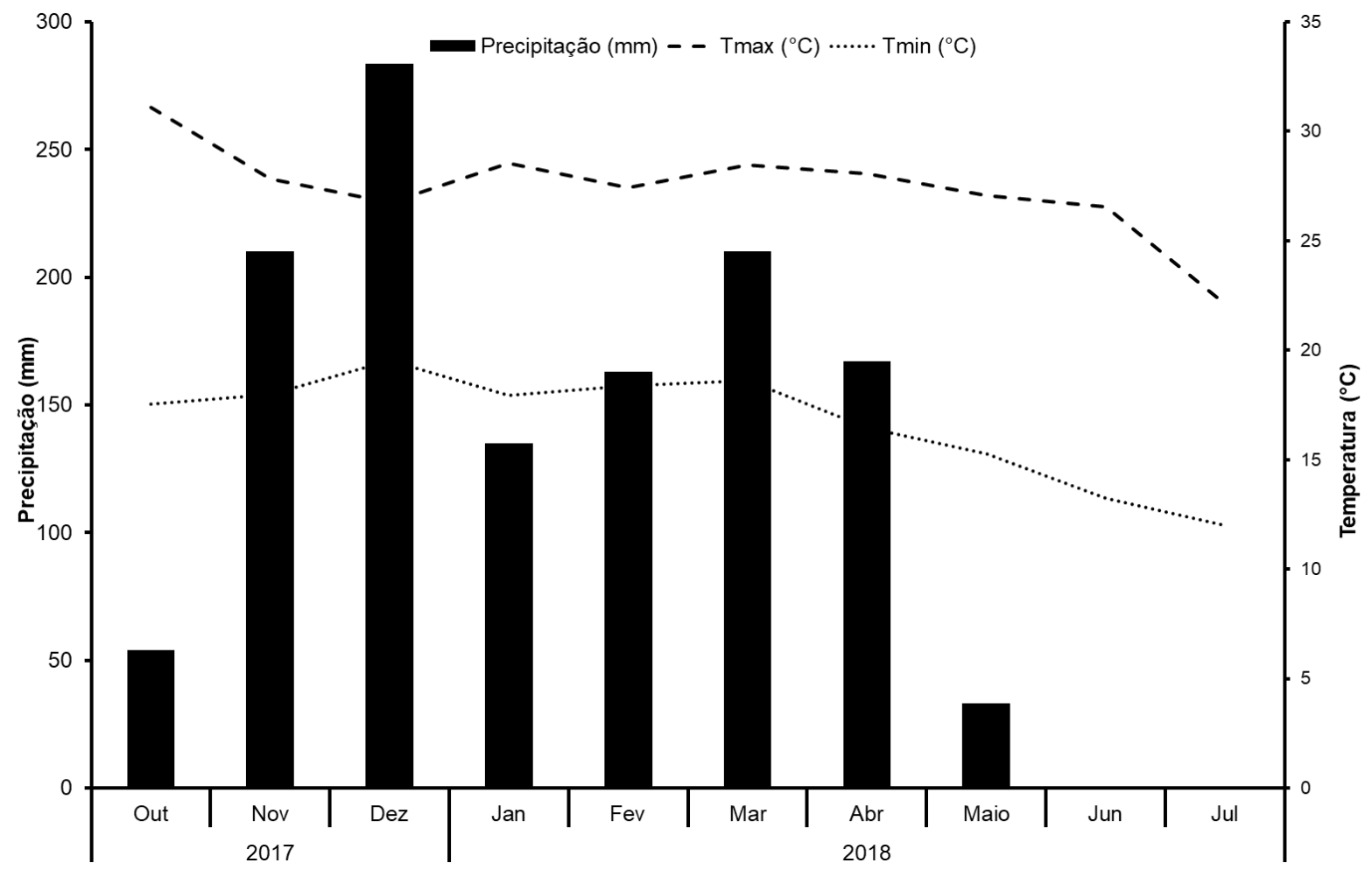

Figura 4. Dados climáticos da área experimental, durante o periodo de realização do ensaio.

A constituição química do solo, nas profundidades de 0 - 20 e de 20 - 40, foi caracterizada e os resultados expressos na Tabela 1. 
Tabela 1. Resultado da análise da fertilidade do solo, camadas de $0-20 \mathrm{~cm}$ e de $20-40 \mathrm{~cm}$.

\begin{tabular}{|c|c|c|c|c|c|c|c|c|c|c|c|}
\hline \multicolumn{12}{|c|}{ Antes do experimento } \\
\hline \multirow{2}{*}{ Amostra } & $\mathrm{pH}$ & $\mathrm{MO}$ & $\mathrm{P}$ - resina & K & $\mathrm{Ca}$ & $\mathrm{Mg}$ & $\mathrm{H}+\mathrm{Al}$ & $\mathrm{Al}$ & SB & CTC & $\mathrm{V} \%$ \\
\hline & $\mathrm{CaCl}$ & $\mathrm{g} \mathrm{dm}^{-3}$ & $\mathrm{mg} \mathrm{dm}-3$ & \multicolumn{7}{|c|}{. } & $\%$ \\
\hline $0-20$ & 5,1 & 49,7 & 13,0 & 3,85 & 36,8 & 9,8 & 72,2 & 1,7 & 50,5 & 122,7 & 41,24 \\
\hline $20-40$ & 4,2 & - & 4,1 & 1,15 & 4,6 & 2,0 & 132,7 & 16,7 & 7,8 & 140,5 & 5,52 \\
\hline \multicolumn{12}{|c|}{ Depois do experimento } \\
\hline \multirow{2}{*}{ Amostra } & $\mathrm{pH}$ & $\mathrm{MO}$ & $\mathrm{P}$ - resina & K & $\mathrm{Ca}$ & $\mathrm{Mg}$ & $\mathrm{H}+\mathrm{Al}$ & $\mathrm{Al}$ & SB & CTC & $\mathrm{V} \%$ \\
\hline & $\mathrm{CaCl}$ & $\mathrm{g} \mathrm{dm}^{-3}$ & $\mathrm{mg} \mathrm{dm}{ }^{-3}$ & \multicolumn{7}{|c|}{ 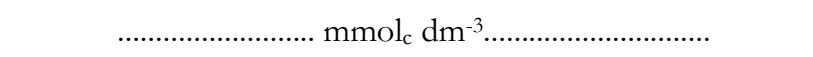 } & $\%$ \\
\hline $0-20$ & 5,1 & 49,0 & 13,0 & 3,15 & 29,0 & 7,5 & 95,0 & 6,2 & 39,6 & 134,6 & 29,48 \\
\hline $20-40$ & 4,2 & - & 4,1 & 1,26 & 5,0 & 2,0 & 92,0 & 4,0 & 8,26 & 100,26 & 8,23 \\
\hline
\end{tabular}

\subsection{Tratamentos e delineamento experimental}

A remobilização foi avaliada em plantas com diferentes cargas de frutos, a fim de simular diferentes situações quanto à força dreno da frutificação. Adotou-se quatro cargas de frutos $(0 \%, 30 \%, 60 \%$ e $100 \%)$ e quatro repetições. As avaliações foram feitas nos quatro estádios fenológicos da frutificação: chumbinho $(\mathrm{CH})$, expansão (EX), granação (GR) e maturação (MT), para identificar a época que a redistribuição seria mais significativa. O experimento foi instalado em blocos ao acaso, com 64 unidades experimentais (dezesseis tratamentos e quatro repetições) (Tabela 2 ). 
Tabela 2. Tratamentos - 4 cargas de frutos x 4 estádios fenológicos

\begin{tabular}{|c|c|c|}
\hline Tratamentos & Carga de frutos por ramo $(\%)$ & Época \\
\hline 1 & 0 & Chumbinho \\
\hline 2 & 30 & Chumbinho \\
\hline 3 & 60 & Chumbinho \\
\hline 4 & 100 & Chumbinho \\
\hline 5 & 0 & Expansão \\
\hline 6 & 30 & Expansão \\
\hline 7 & 60 & Expansão \\
\hline 8 & 100 & Expansão \\
\hline 9 & 0 & Granação \\
\hline 10 & 30 & Granação \\
\hline 11 & 60 & Granação \\
\hline 12 & 100 & Granação \\
\hline 13 & 0 & Maturação \\
\hline 14 & 30 & Maturação \\
\hline 15 & 60 & Maturação \\
\hline 16 & 100 & Maturação \\
\hline
\end{tabular}

O raleio dos frutos foi realizado na planta inteira, no início da fase fruto chumbinho, em conformidade com os tratamentos (Tabela 2). Em seguida foram marcados dois ramos produtivos de cada lado da planta no sentido da entrelinha (quatro ramos por planta). Para identificar a vegetação nova simultânea à carga de frutos (variável conforme o tratamento) foi colocado arame no último par de folhas presente no início do experimento (fruto chumbinho), conforme esquema apresentado na figura 5. 


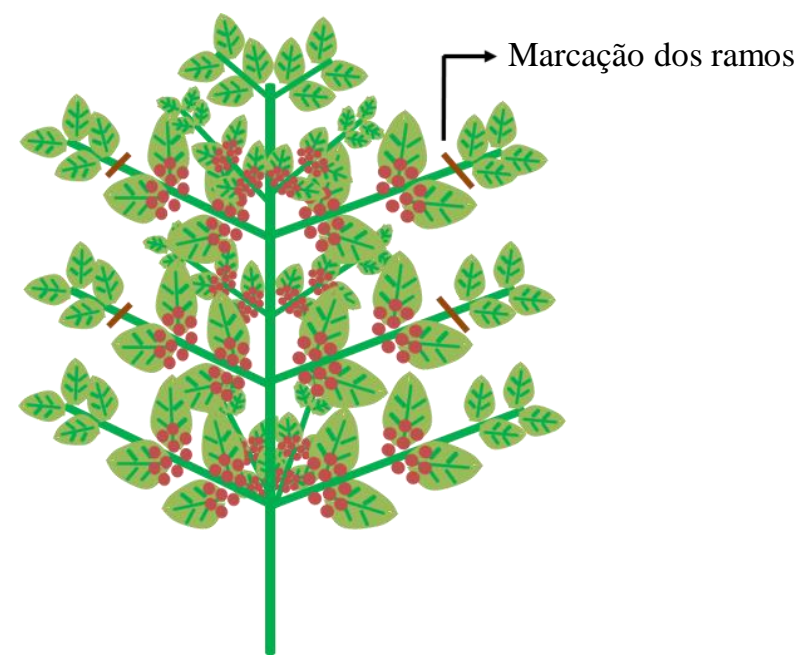

Figura 5. Esquema da separação da parte produtiva da parte vegetativa em cada ramo de café

\subsection{Tratos culturais}

Os tratos culturais, como a dose de nutrientes, controle da irrigação, de pragas, doenças e de plantas daninhas foram feitos pelo gerente da fazenda (Figura 6).

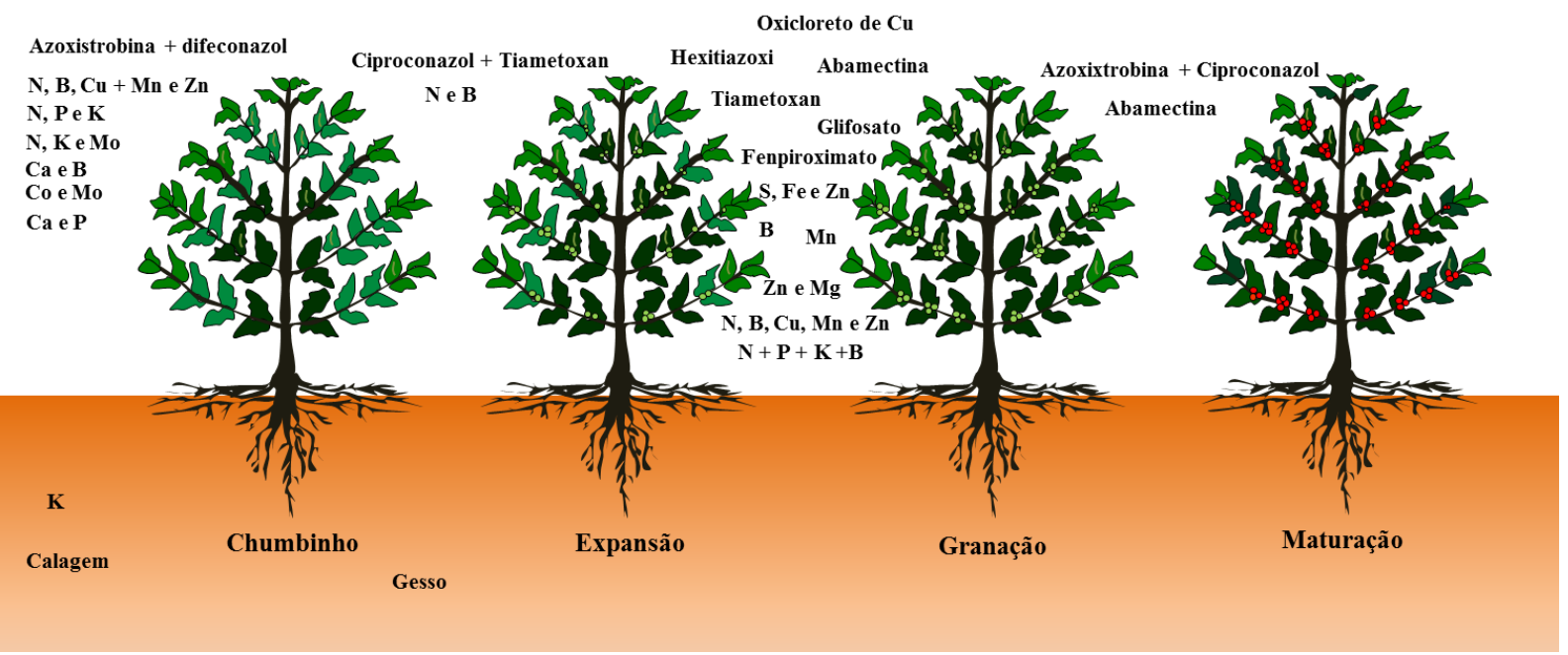

Figura 6. Produtos utilizados para a condução do cafeeiro da área experimental. 


\subsection{Análises}

\subsubsection{Coleta do material vegetal}

A coleta foi realizada nos ramos marcados, dos quais foram coletadas todas as folhas adultas, novas e frutos. Cada tipo de material foi colocado em sacos de papeis devidamente identificados quanto ao tratamento e repetição. O material coletado foi levado para o Núcleo de Pesquisa em Fisiologia e Estresse de Plantas, Centro Universitário de Patos de Minas/UNIPAM para processamento e análise.

\subsubsection{Preparo das amostras}

As folhas e frutos foram lavados com água deionizada para retirar possíveis resíduos, e submetidas à secagem em estufa com circulação de ar a $70{ }^{\circ} \mathrm{C}$ por 36 horas. Posteriormente, as amostras foram trituradas em moinho de facas, e armazenadas.

\subsubsection{Análise química de tecidos vegetais}

As folhas de nós com frutos e nós sem frutos foram colhidas separadamente e preparadas para determinar as concentrações de nutrientes no floema, nas seguintes fases: fruto chumbinho, fruto em expansão, na granação e na maturação.

As concentrações de $\mathrm{P}, \mathrm{K}, \mathrm{Mg}$ e $\mathrm{Zn}$ foram determinadas no EDX, espectrômetro de fluorescência que irradia as amostras com raios-X. Por meio da medida dos raios-X fluorescentes gerados determina-se os elementos e a quantidade presente nas amostras.

A determinação de $\mathrm{N}$ total das folhas foi realizada conforme a metodologia descrita por Silva (1999). As amostras foram colocadas em tubo digestor a qual acrescentam $3 \mathrm{~mL}$ de $\mathrm{H}_{2} \mathrm{SO}_{4}$ 98\% e 1 g de $\mathrm{K}_{2} \mathrm{SO}_{4}+\mathrm{CuSO}_{4}$, e levados para bloco digestor, cuja temperatura foi elevada em $50{ }^{\circ} \mathrm{C}$ a cada 30 minutos até atingir $350{ }^{\circ} \mathrm{C}$. O resultado da digestão é um líquido verde, e após o resfriamento completa-se o tubo com água até $50 \mathrm{~mL}$. O teor de N-total foi obtido pelo método de Kjeldahl, no qual o resultado da digestão foi destilado em meio fortemente alcalino, e a retenção da amônia foi obtida em meio contendo ácido bórico. Posteriormente realizou-se a titulação com $\mathrm{HCl}$.

\subsection{Avaliação da redistribuição (remobilização ou retranslocação)}

\subsubsection{Metodologia adaptada de Maillard et al. (2015)}

A quantidade remobilizada dos nutrientes $(\mathrm{N}, \mathrm{P}, \mathrm{K}, \mathrm{Mg}$ e $\mathrm{Zn})$ foi obtida conforme descrito a seguir:

$$
\mathrm{RE}(\%)=\frac{\text { CNuFolhaCH }- \text { CNuFolhaMT }}{\text { CNuFolhaCH }} \times 100
$$


em que: RE (\%) corresponde a quantidade remobilizada; $\mathrm{CNuFolhaCH}$ a concentração do nutriente nas folhas dos nós com frutos na fase de fruto chumbinho $\left(\mathrm{g} \mathrm{kg}^{-1}\right)$; CNuFolhaMT a concentração do mesmo nutriente nas folhas dos nós com frutos na maturação $\left(\mathrm{g} \mathrm{kg}^{-1}\right)$. Ressalte-se que a mesma foi realizada entre duas fases subsequentes da frutificação (CH-EX; EX-GR; GR-MT) a fim de identificar a época em que a transferência dos nutrientes das folhas para os frutos foi mais acentuada.

\subsubsection{Metodologia adaptada de Zhao et al. (2014)}

A quantidade redistribuída dos nutrientes (N, P, K, Mg e Zn) foi obtida conforme descrito a seguir:

$$
\mathrm{RE}(\%)=\frac{\mathrm{CNuFolhaCH}-\mathrm{CNuFolhaMT}}{\text { CNuFrutoMT }- \text { CNuFrutoCH }} \times 100
$$

em que: $\mathrm{RE}(\%)$ corresponde ao valor relativo à remobilização; $\mathrm{CNuFolhaCH}$ a concentração do nutriente nas folhas dos nós com frutos na fase de fruto chumbinho $\left(\mathrm{g} \mathrm{kg}^{-1}\right)$; CNuFolhaMT a concentração do mesmo nutriente nas folhas dos nós com frutos na maturação $\left(\mathrm{g} \mathrm{kg}^{-1}\right)$; $\mathrm{CNuFrutos} \mathrm{CH}$ corresponde a concentração do mesmo nutriente nos frutos na fase chumbinho $\left(\mathrm{g} \mathrm{kg}^{-1}\right)$; CNuFrutosMT a concentração do respectivo nutriente nos frutos maduros $(\mathrm{g} / \mathrm{kg})$. Ressalte-se que a mesma foi realizada entre duas fases subsequentes da frutificação (CH-EX; EX-GR; GRMT) a fim de identificar a época em que foi maior a transferência dos nutrientes das folhas para os frutos.

Para que os valores obtidos da redistribuição fossem extrapolados em $\mathrm{kg} \mathrm{ha}^{-1}$ (RE, $\mathrm{kg} \mathrm{ha}^{-1}$ ) as folhas associadas aos nós com frutos de todos os ramos de dez plantas foram coletadas no início do experimento, para determinar a massa seca de folhas por planta (MS) (Figura 6). A extrapolação foi obtida pelo produto entre a quantidade de matéria seca (MS, kg/planta), a remobilização (\%) e o número de plantas por hectare (NP/ha): RE $(\mathrm{kg} / \mathrm{ha})=\mathrm{MS}(\mathrm{kg} /$ planta $) \times \mathrm{NP} / \mathrm{ha} \times \mathrm{RE}(\%) / 100$.

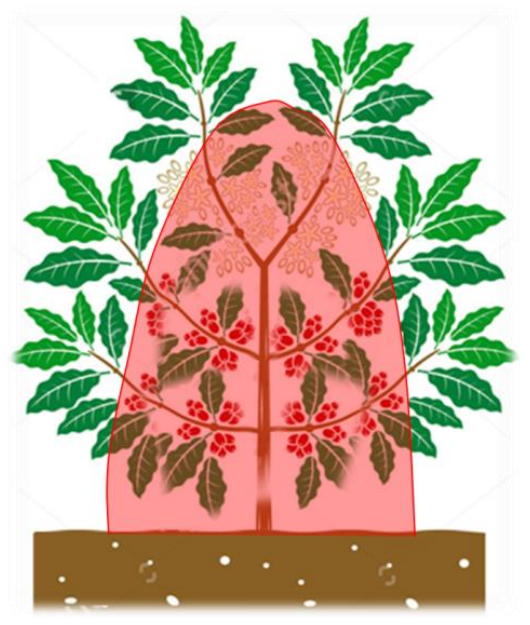

Figura 7. Identificação das folhas associadas aos nós com frutos coletadas para determinar a massa de matéria seca (MS) 


\subsection{Análise Estatística}

Os dados foram submetidos a análise de variância, sendo em esquema fatorial quatro cargas $\mathrm{x}$ quatro épocas, as médias foram comparadas pelo teste tukey a 0,05 de propabilidade por meio do software $\mathrm{R}$ x 64 5.3.5. Os gráficos ajustados utilizando o software Sigma Plot Versão 14.0. 


\section{RESULTADOS E DISCUSSÃO}

Os dados de redistribuição foram calculados seguindo metodologia proposta por Maillard (2015) e Zhao (2014). Na metodologia proposta por Maillard (Figura 8 A), em todas as épocas de estudo houve redistribuição de N, com diferença estatística entre as cargas de frutos e fases de frutificação. $\mathrm{Na}$ fase $\mathrm{CH}-\mathrm{EX}$, as maiores redistribuições foram para as cargas de frutos de 30 e 100\%, entretanto na fase subsequente esse comportamento não se manteve. Para a época entre EX - GR, a maior translocação de $\mathrm{N}$ foi para a carga de $0 \%$ de frutos, mantendo-se constante na fase posterior. O período GR-MT foi o de maior redistribuição para as cargas de frutos 30, 60 e 100\%. Considerando todo o período de frutificação do cafeeiro $(\mathrm{CH}-\mathrm{MT})$ a maior porcentagem de $\mathrm{N}$ resdistribuido para os órgãos drenos foi verificada para a carga de $0 \%$ de frutos.

Para a metodologia proporta por Zhao (Figura 8 B), para o período entre $\mathrm{CH}-\mathrm{EX}$, a maior redistribuição foi verificada para a carga de 30\% de frutos, a fase EX-GR, não apresentou redistribuição de $\mathrm{N}$, em nenhuma das cargas de frutos. Semelhante à metodologia de Maillard, a época entre GR-MT, foi a de maior redistribuição para as cargas de 60 e 100\% de frutos. Já para a carga de 30\% de frutos a maior translocação de $\mathrm{N}$ aconteceu na fase $\mathrm{CH}$ EX. Durante o ciclo frutífero do cafeeiro, considerando a redistribuição entre as épocas CH-MT, a maior redistribuição ocorreu na carga $100 \%$ de frutos.

A planta absorve o nitrogênio nas formas amoniacal ou nítrica, sendo móvel tanto na planta como no solo. É um dos nutrientes mais requeridos pelas plantas, este nutriente é componente estrutural de componentes da célula vegetal, como aminoácidos, proteínas e ácidos nucleicos (TAIZ e ZEIGER, 2013). Quando adicionado de forma equilibrada no período vegetatico o nitrogênio incrementa o crescimento de parte aérea, melhorando a captação de luz e atividade fotossintética. Na cultura do café, a fase de maior demanda desse nutriente, ocorre na fase de granação dos frutos (PEZZOPANE et al, 2003).

O período de maior redistruibuição de N (GR-MT), cargas de 30, 60 e 100\% de frutos, caracteriza-se pela solidificação dos líquidos internos e solidificação dando origem ao grão (CAMARGO e CAMARGO, 2001). E pela alteração de processos metabólicos e modificações químicas (MORAIS et al, 2008). Geromel (2006) relata que a maturação dos frutos tem início com aumento da taxa respiratória e com a síntese de etileno, que acelera o metabolismo do açúcar.

(A)

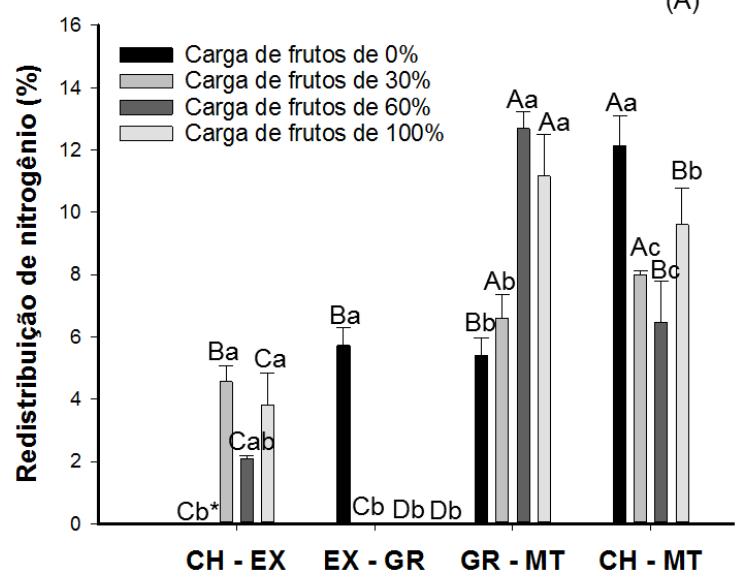

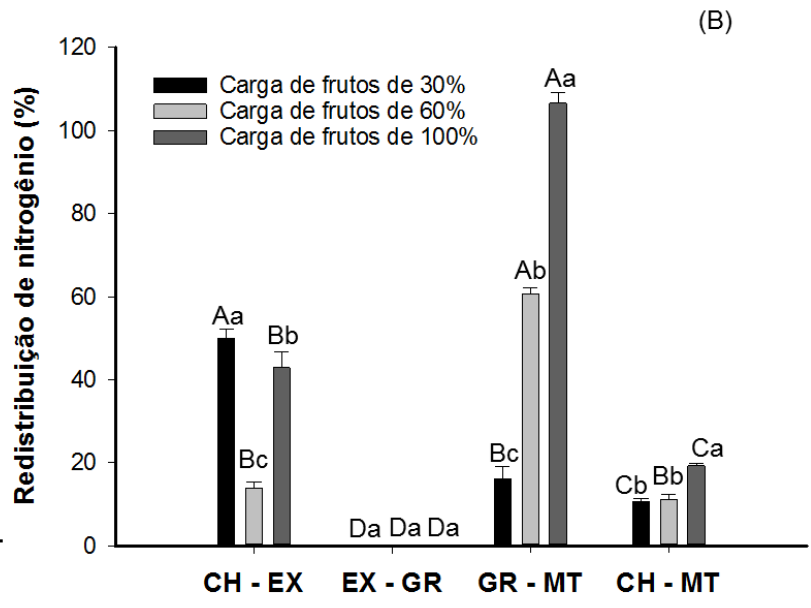

Figura 8. Redistribuição de nitrogênio em plantas de café pelo método de Maillard (A) e pelo método de Zhao (B). *Letras maiúsculas se referem à comparação entre cada fase de frutificação, dentro de cada carga de frutos, enquanto, letras minúsculas se referem à comparação entre as cargas de frutos dentro de cada fase de frutificação. 
Os dados de P apresentaram diferença estatística entre as cargas de frutos em todas as épocas (Figura 9 A). As fases de maior redistribuição de $\mathrm{P}$ variou de acordo com a carga de frutos, para o tratamento sem carga a maior redistribuição ocorreu na fase entre EX-GR, para a carga de 30\% de frutos ocorreu na fase entre CH-EX e para as cargas de 60 e 100\% de frutos a maior redistribuição de P aconteceu na fase entre GR-MT. Assim como para o N, a maior redistribuição considereando todo o ciclo frutífero, foi para a carga de $0 \%$ de frutos, cerca de $2 \%$ do $\mathrm{P}$ das folhas contidas nos nós frutíferos foi redistribuído.

No que se refere a metodologia proposta por Zhao (Figura 9 B), nas quantro épocas as cargas de frutos apresentaram diferença estatística. A fase de maior redistribuição de P variou conforme a carga de frutos $(30 \%$ : $\mathrm{CH}-$ EX, 60\%: GR - MT e 100\%: EX-GR). Ao que se refere a redistribuição total na fase de frutificação, a maior transferência de P foi pela carga de $60 \%$ de frutos.

A fase $\mathrm{CH}$, apresenta baixa taxa de crescimento dos frutos. Essa característica pode ser explicada pela taxa respiratória e de multiplicação celular (CANNEL, 1971). Matiello et al., (2005) ressalta que para essa fase de frutificação não há uma alta demanda por nutrientes, entretanto, no presente trabalho, a redistribuição de P na carga de 30\% de frutos obteve maior redistribuição. Nessa fase, a concentração de P (Figura 15 B) nos frutos foi maior que em todas as outras fases.

(A)

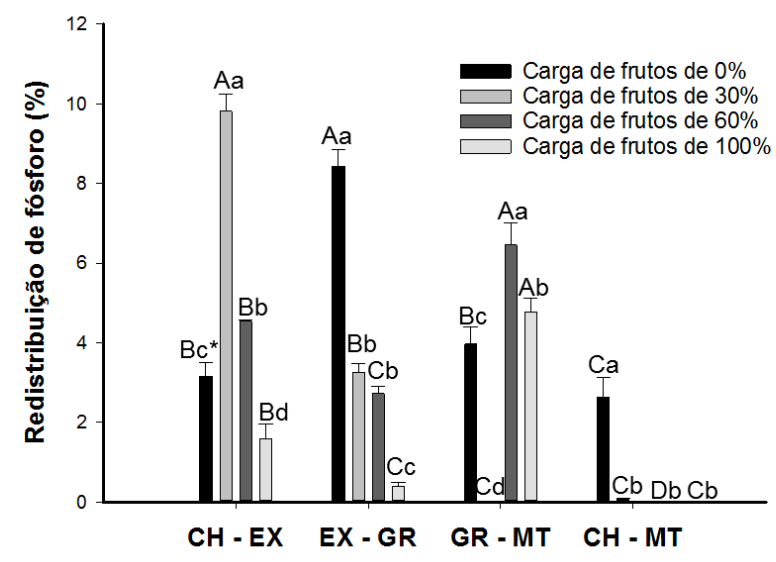

(B)

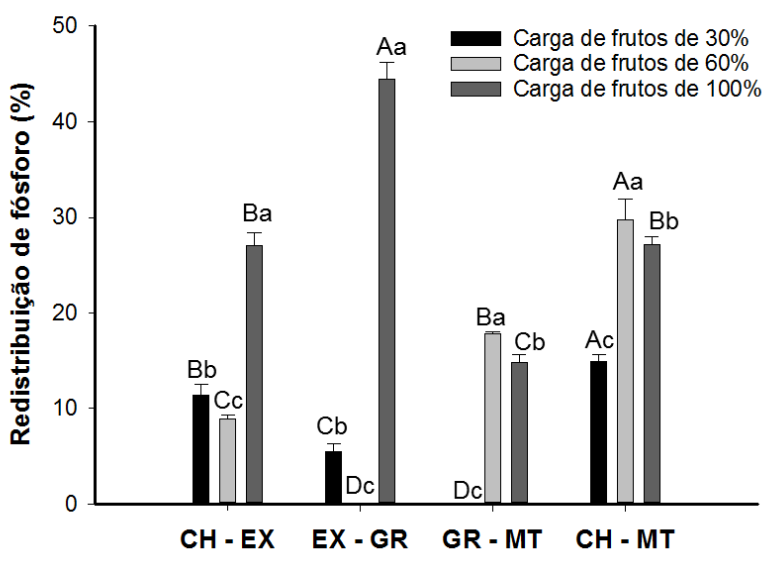

Figura 9. Redistribuição de fósforo em plantas de café pelo método de Maillard (A) e pelo método de Zhao (B). *Letras maiúsculas se referem à comparação entre cada fase de frutificação, dentro de cada carga de frutos, enquanto, letras minúsculas se referem à comparação entre as cargas de frutos dentro de cada fase de frutificação.

Os dados de K, estatisticamente foram diferentes nas fases CH-EX e EX-GR (Figura 10 A). Durante a primeira fase a maior transferência de $\mathrm{K}$ foi dada na carga de $30 \%$ de frutos, porém na fase entre as épocas de EXGR a maior redistribuição foi verificada sem carga de frutos. Nota-se que para o K, a medida que o ciclo frutífero avança, maior é a redistribuição do nutriente, portanto, a maior época de redistribuição para o nutriente $K$, se dá entre as fases de GR- MT. Na fase compreendida entre CH- MT, não houve diferença entre as cargas de frutos quanto a porcentagem de $\mathrm{K}$, redistribuído para os órgãos drenos.

Para os dados referentes à metodologia proposta por Zhao (Figura 10 B), somente o período entre CH-MT não apresentou diferença estatística entre as cargas. $\mathrm{Na}$ fase $\mathrm{CH}-\mathrm{EX}$, foi verificado as maiores redistribuições para as cargas de frutos de 30 e 100\%. Já para a carga de 60\% de frutos a maior transferência de nutrientes, foi verificada na fase GR-MT. 
O K é nutriente com alta mobilidade no floema, exercendo importante papel enzimático, abertura e fechamento de estômato, transporte de açúcares e regulação osmótica (FARMER e JONES, 1942; MENGEL e KIRKBY, 1978; MARSCHNER, 1995; MALAVOLTA, 2006). Devido a seu importante papel o K apresentou alta redistribuição no presente trabalho, os valores de reutilização de $\mathrm{K}$, foram semelhantes aos valores encontrados por Lima Filho e Malavolta (2003), os autores trabalhando com 85Rb marcado, verificaram que a redistribuição de K varia entre 47 e 58\%, enquanto no presente estudo os valores ficaram na ordem de 38 a 50\% (Figura 10A) e 60 a 100\% (Figura 10 B).

(A)

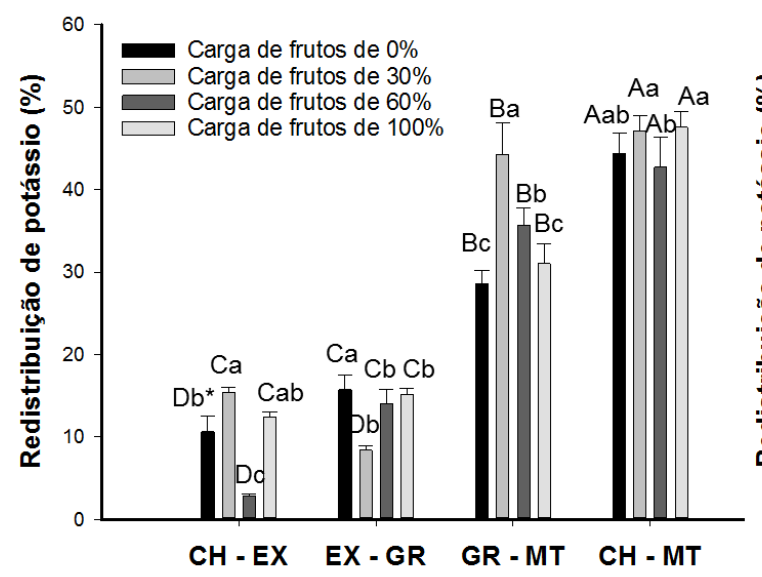

(B)

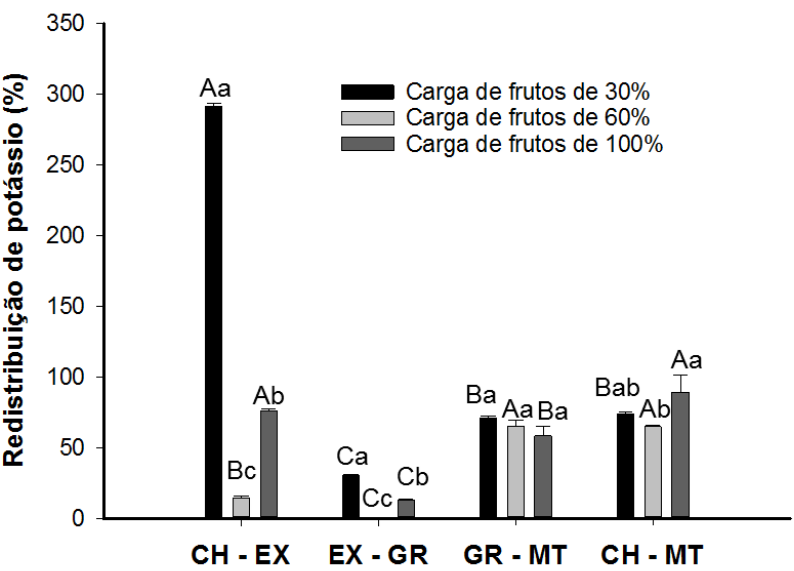

Figura 10. Redistribuição de potássio em plantas de café pelo método de Maillard (A) e pelo método de Zhao (B). *Letras maiúsculas se referem à comparação entre cada fase de frutificação, dentro de cada carga de frutos, enquanto, letras minúsculas se referem à comparação entre as cargas de frutos dentro de cada fase de frutificação.

Quanto ao Mg todas as fases de estudo apresentaram diferença estatística entre as cargas de frutos (Figura 11 A). A maior redistribuição de $\mathrm{Mg}$, para todas as cargas de frutos simuladas aconteceu na fase GR-MT, variando entre $8 \%$ para sem carga $(0 \%)$ e $20 \%$ para uma carga de $60 \%$ de frutos.

A fase CH-EX, não apresentou diferença estatística entre as cargas, entretanto, essa fase apresentou as maiores transferências de Mg para as cargas de 60 e 100\% dos frutos. Na redistribuição do ciclo de frutificação a maior transferência de $\mathrm{Mg}$ foi verificada para a carga de 60\% dos frutos (Figura $11 \mathrm{~B}$ ).

$\mathrm{O} \mathrm{Mg}$ faz parte do átomo central das moléculas de clorofila, esta molécula esta localizada nos cloroplastos, organela onde ocorre a fotossíntese. Outras funções do magnésio estão relacionadas ao transporte de carboidratos, respiração e ativação enzimática.

Os períodos de maior redistribuição de $\mathrm{Mg}$ ocorreram entre as fases GR-MT, para a metodologia de Maillard e CH- EX. A primeira fase tem como característica a elevada taxa respiratória, como já supracitado. A respiração é o processo bioquímico que ocorre nas células e tem como resultado a formação de ATP e NADPH, moléculas responsáveis pela energia nas plantas (TAIZ e ZEIGER, 2013). 
(A)

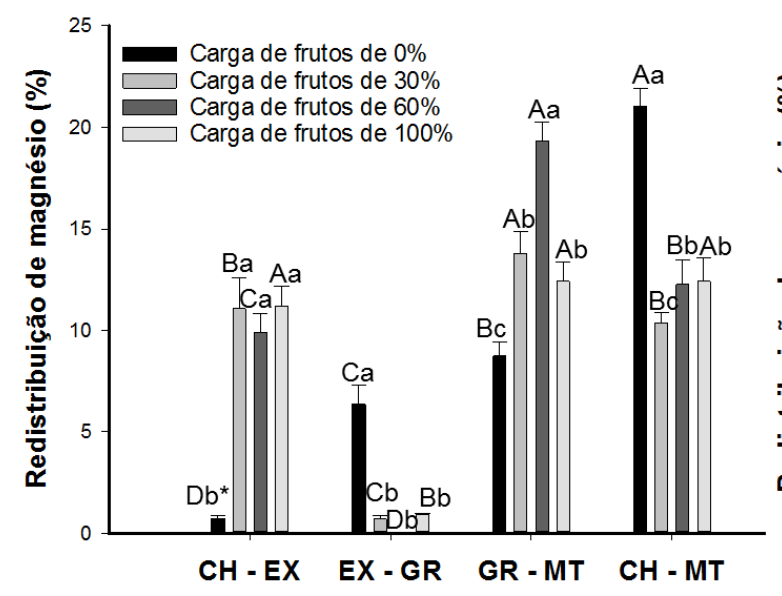

(B)

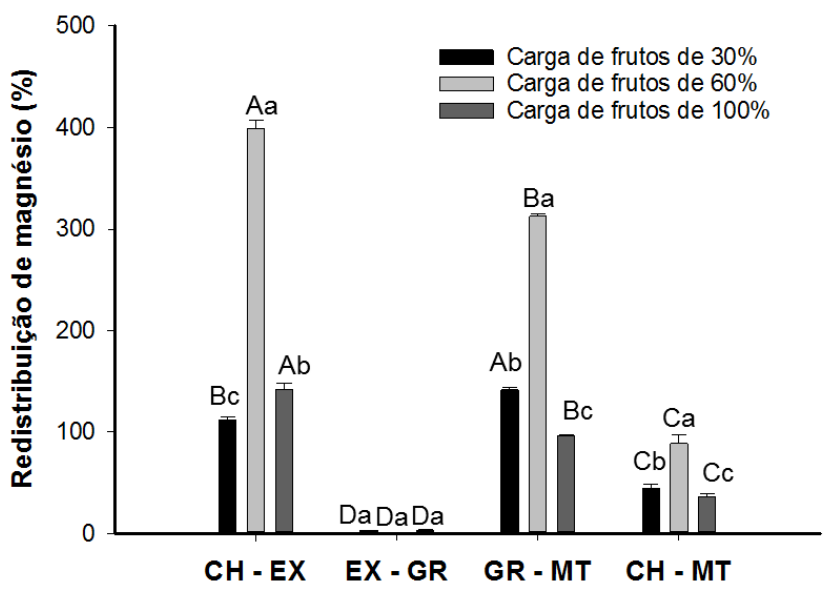

Figura 11. Redistribuição de magnésio em plantas de café pelo método de Maillard (A) e pelo método de Zhao (B). *Letras maiúsculas se referem à comparação entre cada fase de frutificação, dentro de cada carga de frutos, enquanto, letras minúsculas se referem à comparação entre as cargas de frutos dentro de cada fase de frutificação.

Os dados de translocação de $\mathrm{Zn}$ demostram que em todas as épocas de estudo foi verificada diferença estatística entre as cargas de frutos (Figura $12 \mathrm{~A}$ ). A maior redistribuição foi verificada entre as fases de GR-MT, para todas as cargas, sendo a maior translocação de $\mathrm{Zn}$ na carga de $100 \%$ dos frutos.

Na metodologia proposta por Zhao (Figura 12 B), não ocorreu redistribuição de Zn somente na fase EXGR. A maior transferência de $\mathrm{Zn}$ para todas as cargas de frutos foi na primeira época, com superioridade para a carga de $100 \%$ de frutos. Na fase que compreende todo o ciclo frutífero do cafeeiro, a maior redistribuição ocorreu na carga de $30 \%$ de frutos.

Em plantas o Zn tem funções relacionadas a fotossíntese, pois está relacionado a enzima anidrase carbônica, a atividade respiratória, e controle hormonal do ácido indolacético (AIA) (MALAVOLTA, 2006). O período de maior resdistribuição de Zn, apesar de ser considerado um elemento mineral pouco móvel no floema, pela metodologia de Maillard ocorreu entre as fases de GR-MT, porém, entre as fases de EX-GR ocorreu fornecimento de vários produtos que continham $\mathrm{Zn}$ na formulação (Figura 6), tal manejo realizado pela fazenda contribuiu para que os valores redistribuição de $\mathrm{Zn}$ durante esse período fossem extrapolados. 
(A)

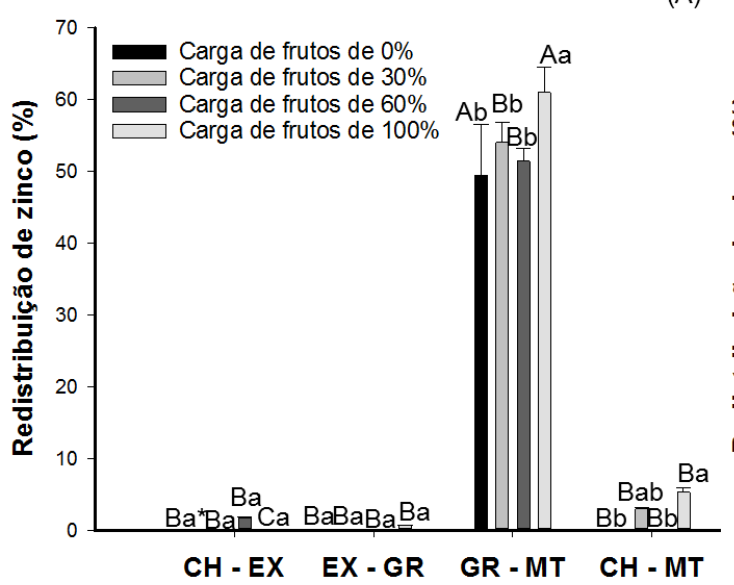

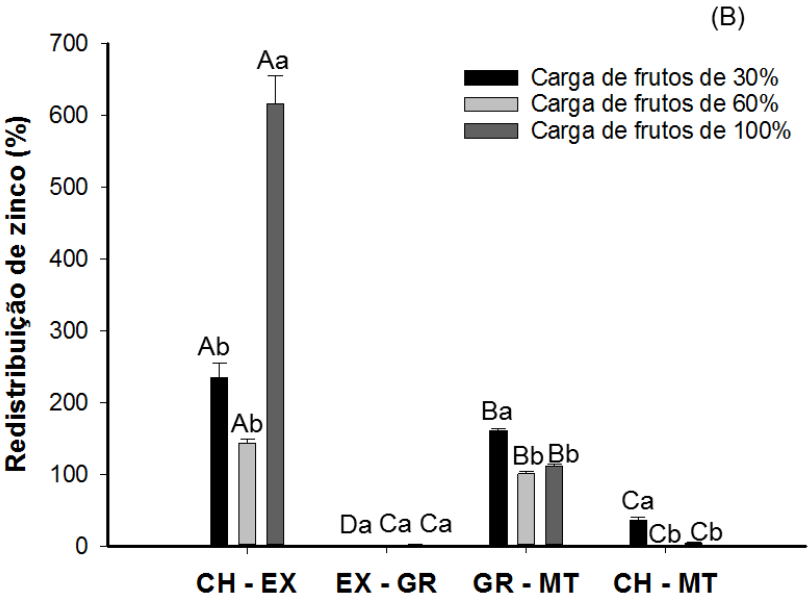

Figura 12. Redistribuição de zinco em plantas de café pelo método de Maillard (A) e pelo método de Zhao (B). *Letras maiúsculas se referem à comparação entre cada fase de frutificação, dentro de cada carga de frutos, enquanto, letras minúsculas se referem à comparação entre as cargas de frutos dentro de cada fase de frutificação.

Os dados de metodologia de Zhao, demonstram alguns valores acima de 100\% de redistribuição, figuras (8 B, 9 B, 10 B, 11 B e 12 B), entretanto, biologicamente não é possível que a redistribuição ocorra acima de $100 \%$. Possivelmente, esses resultados foram encontrados, pois, a metodologia proposta por Zhao, considera a diferença de concentração de nutrientes em dois órgãos (folhas e frutos). O fornecimento de nutrientes aos drenos (frutos) não ocorre somente via folha, podendo ser fornecido via solo, e tal comportamento não pode ser controlado pela presente pesquisa, devido a essa falha foram obtidos valores acima de $100 \%$.

As concentrações de N, P, K, Mg e Zn, nas folhas velhas, folhas novas e frutos são representadas pelas Figuras 13, 14 e 15. Os dados de N (Figura 13 B) demonstram que a diferença entre as cargas de frutos se deu apenas na fase chumbinho, onde a maior concentração estava nas plantas sem frutos. O mesmo comportamento foi verificado para as folhas velhas, nas quais novamente a maior concentração de $\mathrm{N}$ foi verificada nas plantas sem frutos (Figura $13 \mathrm{~A}$ ).

Os teores de $\mathrm{P}$ nas folhas velhas (Figura $13 \mathrm{C}$ ) apresentaram diferença estatística apenas para a coleta realizada na fase de chumbinho, sendo a maior concentração verificada para a carga de 30\% de frutos. Já para as folhas novas (Figura $13 \mathrm{D}$ ) as cargas apresentaram diferença estatística somente para as coletas no estádio chumbinho e granação. No estádio chumbinho a maior concentração é verificada no tratamento sem frutos, no entanto no estádio granação a maior concentração de P nas folhas novas se dá para a carga de 100\% dos frutos.

As concentraçãoes de $\mathrm{K}$ nas folhas velhas (Figura $13 \mathrm{E}$ ) apresentaram diferença estatística entre as cargas de frutos no estádio de granação. A maior concentração de $\mathrm{K}$ nas folhas velhas foi verificada na carga de 30\% dos frutos. É possível verificar ainda que a medida que as épocas de frutificação avançam a concentração de $\mathrm{K}$ nas folhas mais velhas tende a reduzir. Já a concentração de $\mathrm{K}$ nas folhas mais novas (Figura $13 \mathrm{~F}$ ) demonstra diferença estatística entre as cargas somente na fase de expansão dos frutos, assim como nas folhas velhas a maior concentração de $\mathrm{K}$ nas folhas novas refere-se a carga de 30\% de frutos. 

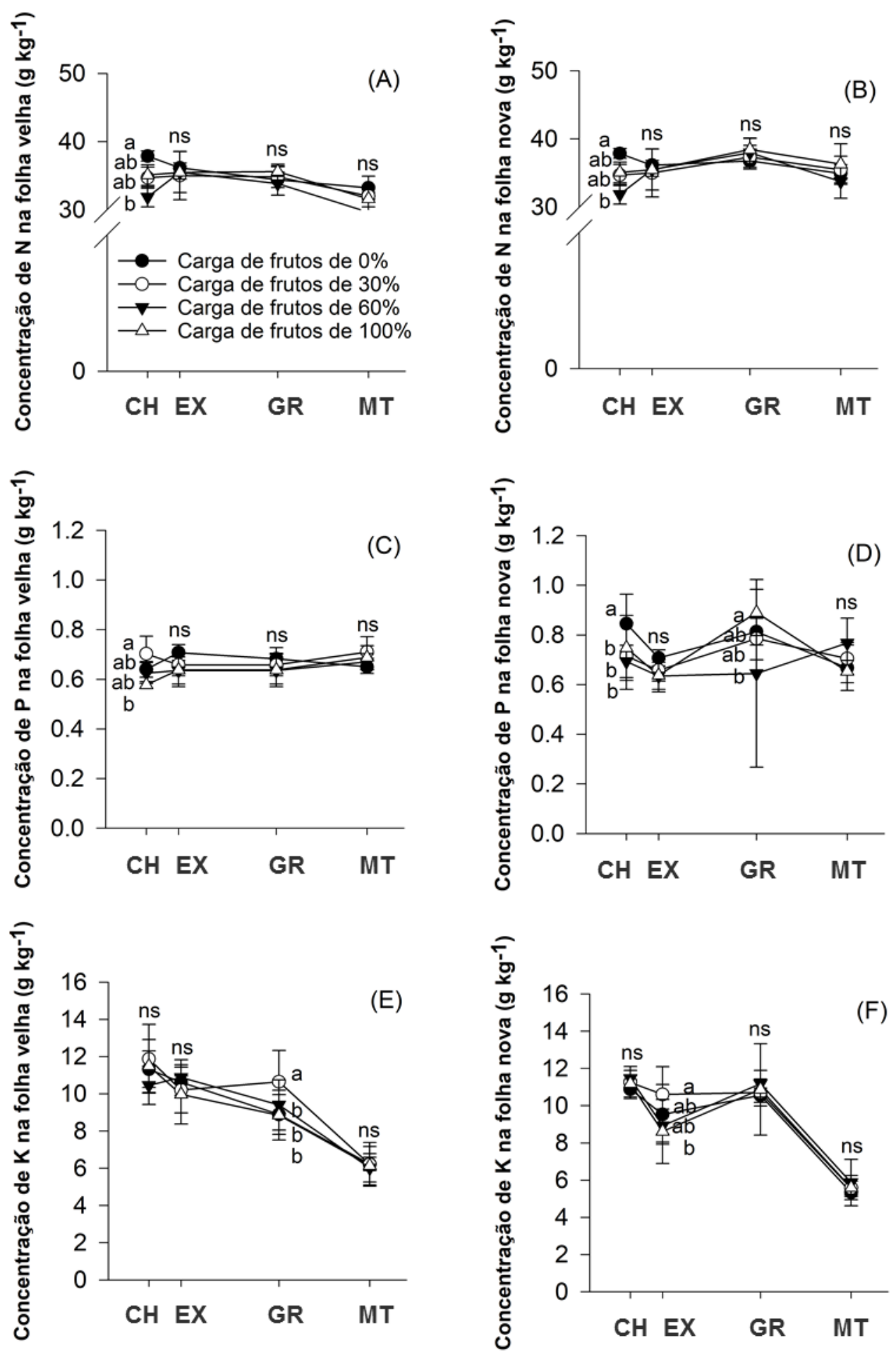

Figura 13. Concentração de $\mathrm{N}$ nas folhas velhas (A) e folhas novas (B); de P nas folhas velhas (C) e folhas novas (D) e de K nas folhas velhas (E) e folhas novas (F).

Os de $\mathrm{Mg}$ não apresentaram diferença estatística entre as cargas de frutos nas épocas de coleta (Figura 14 A, B). Já para a concentração de Zn nas folhas velhas (Figura 14 E) e novas (Figura 14 F) é possível observar que os 
dados apresentaram variações nas épocas de coleta. Para as folhas velhas o Zn apresentou diferença estatística entre as cargas de frutos no estádio de expansão dos frutos. Sendo a maior concentração de Zn para a carga de 100\% de frutos. Já para a concentração de nutrientes nas folhas novas, nota-se a maior diferença no estádio de granação, sendo a maior concentração de Zn verificada para a carga de $30 \%$ de frutos.
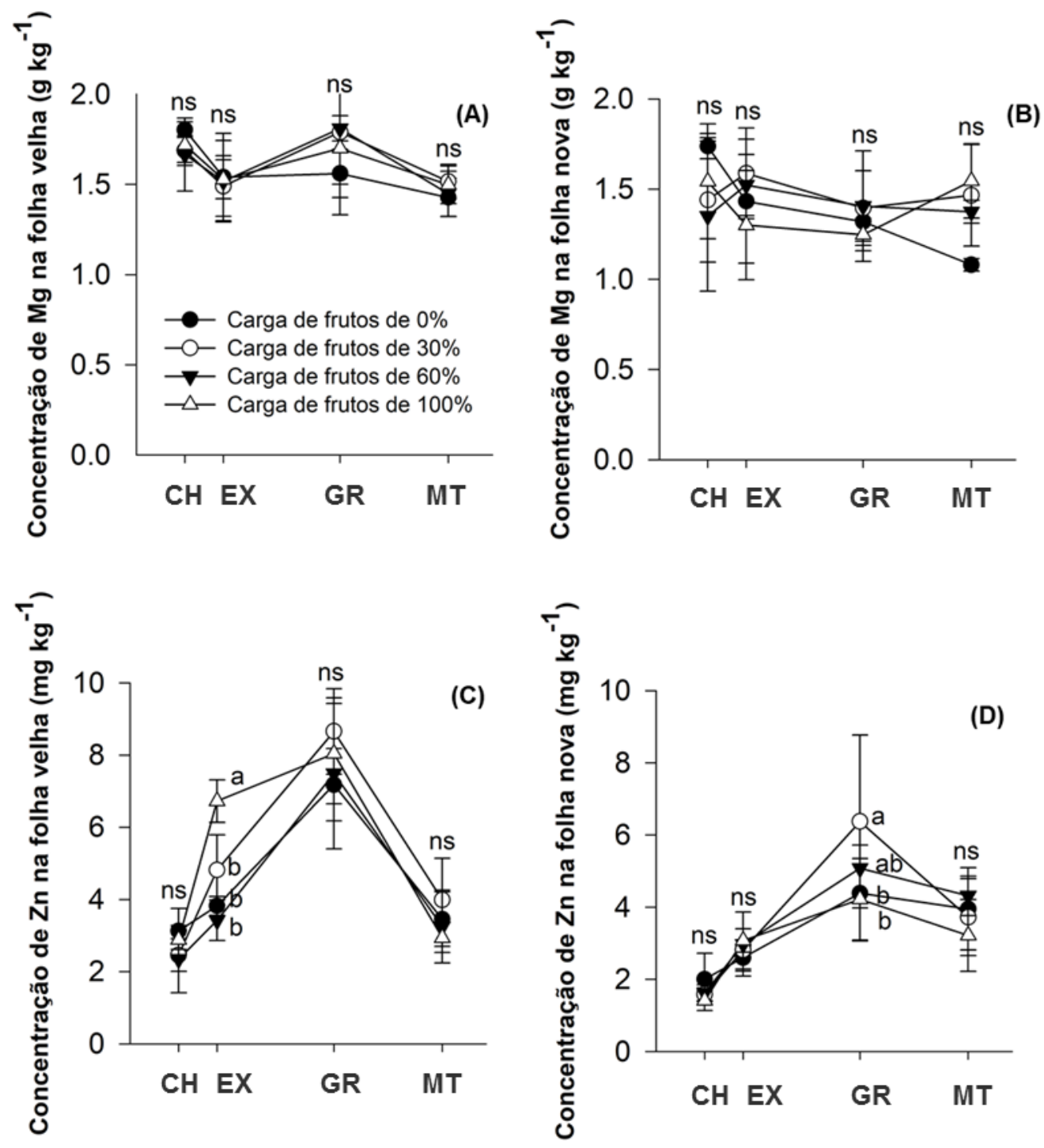

Figura 14. Concentração de Mg nas folhas velhas (A) e folhas novas (B); de Zn nas folhas velhas (C) e folhas novas (D).

A concentração de nutrientes nos frutos foi avaliada em quatro épocas e quatro cargas de frutificação. Os dados de N (Figura 15 A) variaram entre as cargas somente no estádio de maturação, a maior concentração dos frutos foi verificada na carga de 30\% de frutos. Já para os dados de P e K (Figura 15 B e C), as cargas não demonstraram diferença em nenhuma das épocas de coleta. Assim como para o N os dados de Mg (Figura 15 D) apresentaram diferença somente para ultima data de coleta, com a maior concentração de $\mathrm{Mg}$ na carga de 100\% dos frutos.

Os dados de Zn (Figura 15 E) demonstram diferença entre as cargas de frutos nos estádios de granação e maturação, nota-se uma variação de comportamento entre as datas de estudo, pois os maiores valores de $\mathrm{Zn}$ no 
estádio de granação são verificados na carga de $60 \%$ de frutos e ao final da fase de frutificação a maior concentração é verificada na carga de $100 \%$ dos frutos.
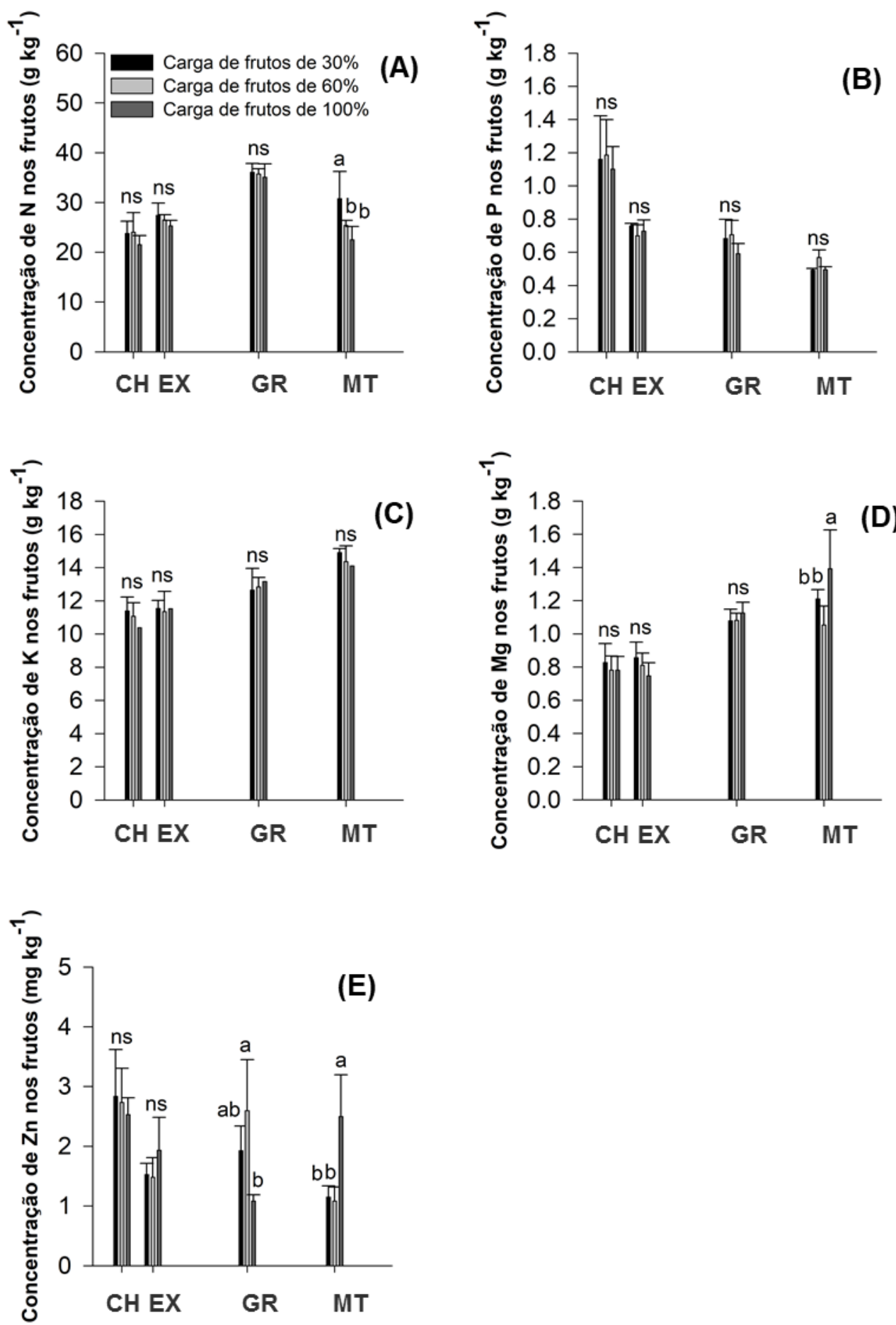

Figura 15. Concentração de N (A), P (B), K (C), Mg (D) e Zn (E) nos frutos de café. 
Considerando todo o período de frutificação (CH-MT), foi calculada a redistribuição em $\mathrm{Kg} \mathrm{ha}^{-1}$ (Tabela 4), a tendência de resdistribuição entre as metodologias foram semelhantes, porém a porcentagem de nutriente redistribuído foi maior para a metodologia proposta pot Zhao et al. (2014). A ordem de redistribuição variou com a metodologia: $\mathrm{K}<\mathrm{Mg}<\mathrm{N}<\mathrm{Zn}, \mathrm{P}$ (metodologia de Maillard et al., 2015), enquanto para a metodologia de Zhao et al. (2014) a redistribuição foi na seguinte ordem: $\mathrm{K}<\mathrm{Mg}<\mathrm{P}<\mathrm{N}<\mathrm{Zn}$.

Os valores de redistribuição extrapolados para $\mathrm{Kg} \mathrm{ha}^{-1}$ (Tabela 3) são baixos, não compensando ser descontados nos valores de adubação, porém, são importantes para compreender como se dá a redistribuição, e o momento que se iniciam as fases de maior redistribuição, auxiliando nos valores de adubação para que não ocorra o esgotamento das reservas das plantas, mantendo as folhas ativas por um mair período de tempo e proporcionando frutos de maior qualidade.

Tabela 3. Redistribuição de N, P, K, Mg e Zn (\% e kg ha-1) pelas metodologias de Maillard e Zhao.

\begin{tabular}{lcccc}
\hline & Maillard $(\%)$ & $\operatorname{Re}\left(\mathrm{kg} \mathrm{ha}^{-1}\right)$ & Zhao $(\%)$ & $\operatorname{Re}\left(\mathrm{kg} \mathrm{ha}^{-1}\right)$ \\
\hline Nitrogênio & 9,61 & 6,77 & 19,29 & 13,66 \\
Fósforo & - & - & 27,02 & 8,13 \\
Potássio & 47,63 & 14,33 & 78,49 & 23,62 \\
Magnésio & 12,10 & 0,435 & 35,99 & 1,29 \\
Zinco & 5,21 & 0,00009 & 4,74 & 0,00043 \\
\hline
\end{tabular}




\section{CONCLUSÕES}

A carga de frutos e a fase de frutificação influenciam a redistribuição de nutrientes. O elemento mais redistribuído é o K; a época de maior transferência dos nutrientes é entre a granação e maturação. Por sua vez, entre as metodologias avaliadas, a proposta por Maillard é mais apropriada, por que considera a concentração de nutrientes de um mesmo órgão entre fases subsequentes. 


\section{REFERÊNCIAS}

ALVES, S. N. R.; REIS, A. R.; FAVARIN, J. L. CAMARGO, F. T.; SALGADO, P. R. Demanda de nutrientes pelas folhas e frutos em café (Coffea arabica) durante a fase produtiva. In: Simpósio de Pesquisa dos Cafés do Brasil (5. : Águas de Lindóia, SP : 2007). Anais. Brasília, D.F. : Embrapa - Café, 2007. (1 CD-ROM), 4p.

AMARAL, J. A. T. Crescimento vegetativo do cafeeiro e suas inter-relações com fontes de nitrogênio, fotoperíodo, fotossíntese e assimilação do nitrogênio. 1991. 139p. Tese (Doutorado em Fitotecnia) Universidade Federal de Viçosa, Viçosa. 1991.

AVALIN, R. L. Veriaciones de los niveles de nitrogens, potássio y cálcio em las hojas de mango (Mangifera indica L.) através de um ciclo de produción. Agronomia Tropical, v. 21, n. 1, p. 3-10, 1971.

BARROS, R.S.; MAESTRI, M.; COONS, P.M.; Source of assimilates for expanding flower buds of coffee. Turrialba, v. 32, p.371-377, 1982.

BATAGLIA, O.C. Transporte e redistribuição de nutrientes via xilema e floema e sua regulação. In: FURLANI, A. M. C.; MEDINA, C. L.; FURLANI, P. R. Curso de atualização em nutrição mineral de plantas perenes. Resumos... Campinas: Instituto Agronômico, 2001. p.14-18.

BONNET, J. A. Influence of varieties and seasons upon mineral nutriente levels of coffee from Puerto Rico. Journal of Agriculture University of Puerto Rico, v. 53, n.3, p. 177-186, 1969.

BORIN, A. L. C.; LANA, R. M. Q.; PEREIRA, H.S. Absorção, acúmulo e exportação de macronutrientes no milho doce cultivado em condições de campo. Ciência agrotécnica, v. 34, p. 1591-1597, 2010.

BRAGANÇA, S.M. Crescimento e acúmulo de nutrientes pelo cafeeiro conilon (Coffea canephora Pierre). 2005. 99f. Tese (Doutorado em Fitotecnia) - Universidade Federal de Viçosa, Viçosa, 2005.

BRANDAO, I.R.; SILVA, D.M.; SOUZA, K.R.D.; BOAS, L.V.V.; SANTOS, M.O.; FABIO MOREIRA DA SILVA, F.M.; ALVES, J.D. Physiological and ultrastructural analysis reveal the absence of a defined abscission zone in coffee fruits. Bragantia, Campinas, v.75, n.4, p.386-395, 2016.

CAMARGO, A. P.; CAMARGO, M. B. P. Definição e esquematização das fases fenológicas do cafeeiro arábica nas condições tropicais do Brasil. Bragantia, v.60, n.1, p. 65-68, 2001.

CAMARGOS, S. L.; MURAOKA, T. Teores, acúmulo e redistribuição de macronutrientes em castanheira-do-brasil. Revista Agricultura Tropical, v.10, p.72-83, 2007.

CAMAYO V.G.C.; CHAVES C.B.; ARCILA P.J.; JARAMILLO R.A. Desarrollo floral del cafeto y su relación con las condiciones climáticas de Chinchiná, Caldas. Cenicafé, v.54, n.1, p.35-49, 2003.

CANNEL, M.G.R. Seasonal patterns of growth and development of arabica coffee in Kenya. Part IV. Effects of seasonal differences in rainfall on bean size. Kenya Coffee, v.36, p.175-180, 1971.

CANNELL, M.G. Physiology of the coffee crop. In: CLIFFORD, M.N.; WILLSON, K.C. Coffee: botany, biochemistry and production of beans and beverage. London: Crom Helm, p.108-134. 1994.

CARVALHO, C. H. S. Cultivares de Café: origem, características e recomendações. Brasília: Embrapa Café, 2008. 334p.

CATANI, R. A.; PELEGRINO, D.; BERGAMIN FILHO, H.; GLORIA, N. A. da; GRANER, C. A. F. A absorção de N, P, K, Ca, Mg e S pelo cafeeiro aos dez anos de idade. Anais da Escola Superior de Agricultura "Luiz de Queiroz”, Piracicaba, v.22, p. 81-89, 1965. 
CHAVES, J. C. D. Concentração de nutrientes nos frutos e folhas e exportação de nutrientes pela colheita durante um ciclo produtivo do cafeeiro (Coffea arabica L. cv. Catuaí). 1982. 131p. Dissertação (Mestrado em Solos e Nutrição de Plantas). Escola Superior de Agricultura Luiz de Queiroz, Universidade de São Paulo, Piracicaba, 1982.

CLEMENTE, J. M. Nutrição nitrogenada e potássica afetando crescimento, produção, composição química e qualidade da bebida de Coffea arabica L. 2010. 52p. Dissertação (Mestrado em Fitotecnia). Universidade Federal de Viçosa, Viçosa. 2010.

CORRÊA, J. B.; GARCIA, A. W. R.; COSTA, P. C. Extração de nutrientes pelos cafeeiros Mundo Novo e Catuaí. In: CONGRESSO BRASILEIRO DE PESQUISAS CAFEEIRAS, 13, 1986, São Lourenço. Anais... Rio de Janeiro: Instituto Brasileiro do Café, 1986. p.35-41.

CORTEZ, J. G. Efeito de espécies e cultivares e do processamento agrícola e industrial nas características da bebida do café. 2001. 71p. Tese (Doutorado em Fitotecnia) - Escola Superior de Agricultura Luiz de Queiroz, Piracicaba.

DaMATTA F.M.; RAMALHO J.D.C. Impacts of drought and temperature stress on coffee physiology and production: a review. Brazilian Journal of Plant Physiology, v.18, p.55-81, 2006.

DaMATTA, F. M.; AMARAL, J. A. T.; RENA, A. B. Growth periodicity in trees of Coffea arabica L. in relation to nitrogen supply and nitrate reductase activity. Field Crops Research, v. 60, p. 223-229, 1999.

DaMATTA, F.M.; RONCHI, C.P.; MAESTRI, M.; BARROS, R.S. Ecophysiology of coffee growth and production. Brazilian Journal of Plant Physiology, v.19, p.14, p.485-510, 2007.

DENTAN, E. Étude microscopique du développement et de la maturation du grain de café. In: COLLOQUE SCIENTIFIQUE INTERNATIONAL SUR LE CAFÉ, 11, Lomé, 1985. Resumos. Paris: ASIC, 1985. p. 381-398.

DESCROIX, F.; SNOECK, J. Environmental factors suitable for coffee cultivation. In: WINTGENS, J.N. Coffee: growing, processing, sustainable production: a guidebook for growers, processors, traders, and researchers. $1^{\mathrm{a}}$ ed. Weinheim: Wiley, 2004, p.164-177.

DISTELFELD, A.; AVNI, R.; FISCHER, A. M. Senescence, nutriente remobilization, and yield wheat and barley. Journal of Experimental Botany, v.65, n.14, p. 3783- 3798, 2014.

EPSTEIN, E.; BLOOM, A. J. Nutrição Mineral de Plantas: princípios e perspectivas. Londrina: Planta, 2006. 403 p.

FAGAN, E.B.; SOUZA, C.H.E.; PEREIRA, N.M.B.; MACHADO, V.J. Efeito do tempo de formação do grão de café (Coffea sp.) na qualidade da bebida. Bioscience Journal, v. 27, n. 5, p. 729-738, 2011.

FAQUIN, V. Nutrição Mineral de Plantas (Especialização em Solos e Meio Ambiente) - Universidade Federal de Lavras, Lavras, 2005.

FARMER, S. N.; JONES, D. A. Influence of Potassium on Sugar Metabolism. Nature, v. 150, p. 768-769, 1942.

FAVARIN, J. L.; NETO, A. P.; TEZOTTTO, T.; MARTINS, P. O.; TEIXEIRA, P. P. C. Correção do magnésio no solo é essencial ao cafeeiro. Visão Agrícola, n.12, p. 76-78, 2013.

FERrÃO, M. A. G.; FERRÃO, R. G.; FONSECA, A. F. A.; VERDiM FILHO, A. C.; VOLPI, P. S. Café Conilon. Vitória: INCAPER, 2007. 702 p.

FRANCO, C.M. Translocação lateral de N, P e K no cafeeiro. In: CONGRESSO BRASILEIRO de PESQUISAS CAFEEIRAS, $10^{\circ}$. Poços de Caldas, 1983. Rio de Janeiro, IBC-GERCA. p. 01-02. 
GEORGE, A. P.; NISSEN, R. J.; CARSELDINE, M. L. Effect of season (vegetative flushing) and leaf position on the leaf nutriente compositon of Annona spp. Hybrid cv. Pink's Mammoth in south-eastern Queensland. Australian Journal of Experimental Agriculture, v.29, p.587-595, 1989.

GEROMEL, C. Metabolismo da sacarose em frutos do café. 2006, 115p. Tese (Doutorado em Biologia Vegetal) - Universidade de Campinas, Campinas, 2006.

GOPAL, N.H.; RAJU, K.I.; VENKATARAMANAN, D.; JANARDHAN, K.V. Physiological studies on flowering in coffee under South India conditions. III. Flowering in relation to foliage and wood starch. Turrialba, v. 25, p.239$242,1975$.

HIROCE, R. Diagnose foliar em cafeeiro. In: MALAVOLTA, E.; YAMADA, T.; GUIDOLIN J. A. Nutrição e adubação do cafeeiro. Instituto da Potassa \& Fosfato (EUA), Instituto Internacional da Potassa (SUIÇA). Piracicaba, p. $117-137,1981$.

IKAN, R. Natural Products: A Laboratory Guide. New York: Harcourt Brace Jovanovich Publishers, 1991, 226p.

JULIA, C.; WISSUWA, M. KRETZSCHMAR, T.; JEONG, K.; ROSE, T. Phosphorus uptake, partitioning and redistribution during grain filling in rice. Annals of Botany, v. 118, p. 1151-1162, 2016.

LAVIOLA, B. G. Alocação de fotoassimilados e nutriente em folhas e frutos de cafeeiro em diferentes altitudes de cultivo. 2007. 136p. Tese (Doutorado em Fitotecnia) - Universidade Federal de Viçosa, Viçosa, 2007.

LAVIOLA, B. G.; MARTINEZ, H. E. P.; SOUZA, R.B.; VENEGAS, V.H.A. Dinâmica de P e S em folhas, flores e frutos de cafeeiro arábico em três níveis de adubação. Bioscience Journal, v. 23, p. 29-40, 2007 b.

LAVIOLA, B. G.; MARTINEZ, H. E. P.; SOUZA, R.B.; VENEGAS, V.H.A. Dinâmica de Cálcio e Magnésio em folhas e frutos de Coffea arabica. Revista Brasileira Ciência do solo, v. 31, p. 319-329, 2007.

LEMOINE, R.; CAMERA, S.; ATANASSOVA, R.; DÉDALDÉCHAMP, F.; ALLARIO, T.; POURTAU, N.; BONNEMAIN, J.; LALOI, M.; COUTOS-THÉVENOT, P.; MAUROUSSET, L.; FAUCHER, M.; GIROUSSE, C.; LEMONNIER, P.; PARRILLA, J.; DURAND, M. Source-to-sink transport of sugar and regulation by environmental factors. Frontiers in Plant Science, v.4, n.272, p.1-21, 2013.

LIMA FILHO; O. F.; MALAVOLTA, E. Studies on mineral nutrition of the coffee plant (Coffea arabica L. cv. catuaí vermelho). lxiv. remobilization and re-utilization of nitrogen and potassium by normal and deficient plants. Brasilian Journal of Biology, v.63, n.3, 481-490, 2003.

LIMA, R. L. S.; SEVERINO, L. S.; CAZETTA, J. O.; AZEVEDO, C. A. V.; SOLIATTI, V. ARRIEL, N. H. C. Redistribuição de nutrientes em folhas de pinhão-manso entre estádios fenológicos. Revista Brasileira de Engenharia Agrícola e Ambiental, v. 15, p. 1175-1179, 2011.

MAILLARD, A.; DIQUÉLOU, S.; BILLARD, V.; LAINÉ, P.; GARNICA, M.; PRUDENT, M.; GARCIA-MINA, J. M.; YVIN, J. C.; OURRY, A. Leaf mineral nutriente remobilization during leaf senescence and modulation by nutriente deficiency. Frontiers in Plant Science, v.6, p. 1-15, 2015.

MAJEROWICZ, N.; SÖNDAHL, M. R. Induction and differentiation of reproductive buds in Coffea arabica L. $\mathrm{m}$ Brazilian Journal of Plant Physiology, Viçosa, v.17, n.2, p.247-254, 2005.

MALAVOLTA, E. Manual de nutrição mineral de plantas. São Paulo: Agronômica Ceres, 2006. 638p.

MALAVOLTA, E. Nutrição mineral e adubação do citros. Boletim técnico Instituto Potassa. v.5, p. 13-71, 1979.

MALAVOLTA, E.; LIMA FILHO, O. F. Nutrição mineral (e adubação) do cafeeiro - lavouras tradicionais, adensadas, irrigadas, arborizadas e orgânicas. In: Simpósio de Pesquisa dos Cafés do Brasil (1. : 2000 : Poços de Caldas, MG). Palestras. Brasília, D.F. : Embrapa Café, 2002. (374p.), p. 331-353. 
MARTINEZ, C.A.; MAESTRI, M.; BARROS, R.S.; DaMATTA, F.M. Photosynthetic behaviour of coffee (Coffea arabica) fruits. In: Annals of the 25 Reunião Anual da Sociedade Brasileira de Bioquímica e Biologia Molecular. Caxambu, Brazil, E-19. 1996.

MARTINEZ, H. E. P.; CLEMENTE, J. M.; LACERDA, J. S.; NEVES, Y. P.; PEDROSA, A.W. Nutrição mineral do cafeeiro e qualidade da bebida. Revista Ceres, v.61, p. 838-848, 2014.

MATIELLO, J. B. et al. Cultura de Café no Brasil: manual de recomendações. Rio de Janeiro: MAPA/PROCAFE, 2010. 542 p.

MATIELLO, J.B.; SANTINATO, R.; GARCIA, A. W. R.; FERNANDES, D.R. Cultura do café no Brasil: novo manual de recomendação. Rio de Janeiro: MAPA /PROCAFÉ, 2005. 438p.

MELO, E.M.; GUIMARÃES, P.T.G.; SILVA, E.B.; NOGUEIRA, F.D. Efeito da aplicação foliar de sulfato de zinco na produção do cafeeiro (Coffea arabica L.). Ciência e Agrotecnologia, v.23, p.84-95, 1999.

MELOTTO, E. Mobilização de carboidratos pelos botões florais de café (Coffea arabica L.) em expansão. 1987. 47p. Dissertação (Mestrado) - Universidade Federal de Viçosa, Viçosa.

MENGEL, K.; KIRKBY, E. A. Principles of plant Nutrition. Berne/; International Potash Institute, 1978. 593p.

MORAIS, H. CAMARONI, P. H.; SEIKOGUTSHI, M.; RIBEIRO, A. M. A. Escala fenológica detalhada da fase reprodutiva de Coffea arabica. Bragantia, v. 67, p. 257-260, 2008.

MOSCARDINI, D.B., Mobilização de açúcares totais pelos grãos de café (Coffea arabica L.) em desenvolvimento. 2017, 23p. Trabalho de conclusão de curso (Graduação em Agronomia) - Escola de Ensino Superior "Luiz de Queiroz", Piracicaba.

NETO, A. P. Metabolismo do nitrogênio e concentração de nutrientes no cafeeiro irrigado em razão da dose de N. Dissertação (Mestrado em Fitotecnia) 2009, 93p. Escola Superior de Agricultura Luiz de Queiroz, Universidade de São Paulo, Piracicaba, 2009.

OHIOKPEHAI, O.; BRUMEN, G.; CLIFFORD, M. N. The chlorogenic acids contend of some peculiar green coffee beans and implications for beverage quality. In: COLLOQUE SCIENTIFIQUE INTERNATIONAL SUR LE CAFÉ, 10, Salvador, 1982. Resumos. Paris: ASIC, 1982. p.177-185.

PEZZOPANE, J. R. M. et al. Escala para avaliação de estádios fenológicos do cafeeiro arábica. Bragantia, Campinas, v. 62, n. 3, p. 499-505, 2003.

QUEIROZ-VOLTAN, R.B.; FAHL, J.I.; CARELLI, M.L.C. Diferenciação floral em cafeeiro arábica (Coffea arabica L.) sob diferentes níveis de radiação. Coffee Science, v. 6, n.3, p.256-268, 2011.

REIS, P.R.; CUNHA, R.L. Café arábica: do plantio à colheita. Lavras: EPAMIG, 2010. 896p.

RENA, A.B.; MALAVOLTA, E.; ROCHA, M. YAMADA, T. Cultura do cafeeiro: fatores que afetam a produtividade. 1 Ed. Piracicaba: POTAFOS, 1986. 447p.

SFREDO, G. J.; BORKET, C. M. Deficiência e toxidade de nutrientes em plantas. Londrina: EMBRAPA SOJA, 2004.

SILVA, E. B.; NOGUEIRA, F. D.; GUIMARÃES, P.T.G. Qualidade dos grãos de café em função de doses de potássio. Acta Scientiarum, v. 24, p.1291-1297, 2002.

SILVA, F.C. (Ed.). Manual de Análises Químicas de Solos, Plantas e Fertilizantes, $1^{\text {a }}$ ed., Embrapa Comunicação para Transferência de Tecnologia: Brasília, 1999. 
SOUZA, L. T. Nutrient demand for vegetation and fruiting of Coffea arabica L. 2018. 33p. Dissertação (Mestrado em Fitotecnia). Escola Superior de Agricultura Luiz de Queiroz, Universidade de São Paulo, Piracicaba.

TAIZ, L.; ZEIGER, E. Fisiologia vegetal. 3.ed. Porto Alegre: Artmed, 2013. 918p.

VAAST, P.; ANGRADAND, J.; FRANK, N.; DAUZAT, J.; GÉNARD, M. Fruit load and branch ring-barking affect carbono allocation and photosynthesis of leaf and fruit of Coffea arabica in the field. Tree Physiology, v. 25, 753-760, 2005.

VALARINI, V. Demanda de macronutrientes pelas folhas e frutos em cultivares de café arábica de porte baixo, 2005, 87p. Dissertação (Mestrado em Agricultura Tropical e Subtropical) - Instituto Agronômico, Campinas.

WANDER, A.; FAGUNDES, A. Nutrição do Cafeeiro, Macro e Micronutrientes, Recomendações e Racionalização. Fundação Procafé, 2012. Disponível em: http://fundacaoprocafe.com.br/sites/default/files/2\%20-

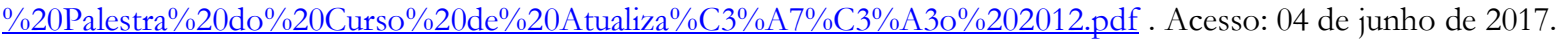

ZHAO, X.; ZENG, S.H.; FATICHIN, S.A.; ARIMA S. Varietal difference in nitrogen redistribuition from leaves and its contribution to seed yield in soybean. Plant Production Science. v.17, p.103-108, 2014. 